\title{
Evaluation Method of the Gas Hydrate and Free Gas System and Its Application in the Shenhu Area, South China Sea
}

\author{
Pibo Su $\mathbb{D}^{1,2,3,4}$ Tingwei Li $\mathbb{D}^{1,2,4}$ Shurong Liang, ${ }^{5}$ Jinqiang Liang, ${ }^{1,2}$ Xiaoxue Wang, ${ }^{1,2}$ \\ Xiaoming Wan, ${ }^{1,2}$ Feifei Wang, ${ }^{1,2}$ and Fang Liu ${ }^{1,2}$ \\ ${ }^{1}$ Guangzhou Marine Geological Survey, China Geological Survey, Guangzhou 510760, China \\ ${ }^{2}$ Gas Hydrate Engineering Technology Center, China Geological Survey, Guangzhou 510075, China \\ ${ }^{3}$ Hubei Key Laboratory of Marine Geological Resources, China University of Geosciences, Wuhan 430074, China \\ ${ }^{4}$ Southern Marine Science and Engineering Guangdong Laboratory, Guangzhou 511458, China \\ ${ }^{5}$ Beijing Dongfang Lianchuang Geophysical Technology Co. Ltd., Beijing 100083, China \\ Correspondence should be addressed to Tingwei Li; litingwei2020@163.com
}

Received 1 March 2021; Revised 15 June 2021; Accepted 30 August 2021; Published 5 October 2021

Academic Editor: Huazhou Li

Copyright (C) 2021 Pibo Su et al. This is an open access article distributed under the Creative Commons Attribution License, which permits unrestricted use, distribution, and reproduction in any medium, provided the original work is properly cited.

\begin{abstract}
As a new alternative energy source, gas hydrate has attracted wide attention all over the world. Since gas hydrate is always associated with free gas, the evaluation of the gas hydrate and free gas system is an important aspect of hydrate reservoir exploration and development. In this study, based on identifying gas hydrate and free gas by well logging, the seismic reflection characteristics of gas hydrate and free gas are determined by an accurate well-to-seismic calibration method. On account of seismic reflection characteristics, AVO attributes are used to identify gas hydrate and free gas qualitatively. Using prestack and poststack inversion to get the ratio of $P$-wave impedance and $P$-wave-to- $S$-wave velocities, we determine the three-dimensional space distribution of gas hydrate and free gas, predict their effective porosity and saturation, and eventually achieve the meticulous depiction of gas hydrate and free gas in the body, which is necessary in subsequent estimation of gas hydrate and free gas resources. Results show that according to logging interpretation, gas hydrate of the B-well is located in the depth range of $1460-1510 \mathrm{mbsl}$ and free gas is in 1510-1542 mbsl. Moreover, gas hydrate of the A-well is located in the depth range of 1425-1512 mbsl, and no obvious free gas is identified. Gas hydrate is located above free gas and distributed continuously. In plane form, gas hydrate and free gas both present subelliptical distribution in the NW-SE direction. Gas hydrate has an effective porosity of $0.30-0.40$, an average saturation of $0.33-0.40$, and an effective thickness of $3.0-10.5 \mathrm{~m}$, whereas free gas possesses an effective porosity of $0.35-0.40$, a saturation of $0.24-0.32$, and an effective thickness of $2.0-5.0 \mathrm{~m}$.
\end{abstract}

\section{Introduction}

Natural gas hydrate is a kind of crystalline compounds composed of natural gas and water under high pressure and low temperature, which is distributed in deep-water sediments and the permafrost [1-3]. Gas hydrate is considered one of the most potential new clean energies to replace coal, oil, and gas in the $21^{\text {st }}$ century, and it is also a new energy with abundant reserves that have not been fully exploited [4-6]. Since natural gas hydrate is a kind of clean energy with great potential and has a positive impact on greenhouse effect and marine ecosystem, the United States, Canada, Japan, South
Korea, and India are committed to the exploration and development of natural gas hydrate $[4,7-13]$.

There is a great prospect of gas hydrate resources in China's vast jurisdictional sea, exclusive economic zone, and permafrost region [14-16]. The South China Sea has favorable geological, geomorphic, and geochemical conditions for natural gas hydrate accumulation [17-24]. Regional marine geological survey and oil and gas exploration show that the South China Sea is rich in natural gas hydrate resources [17, 20, 23, 25-29].

Recent studies have shown that gas hydrate and free gas coexist in the Hydrate Ridge in offshore Oregon [30], the 


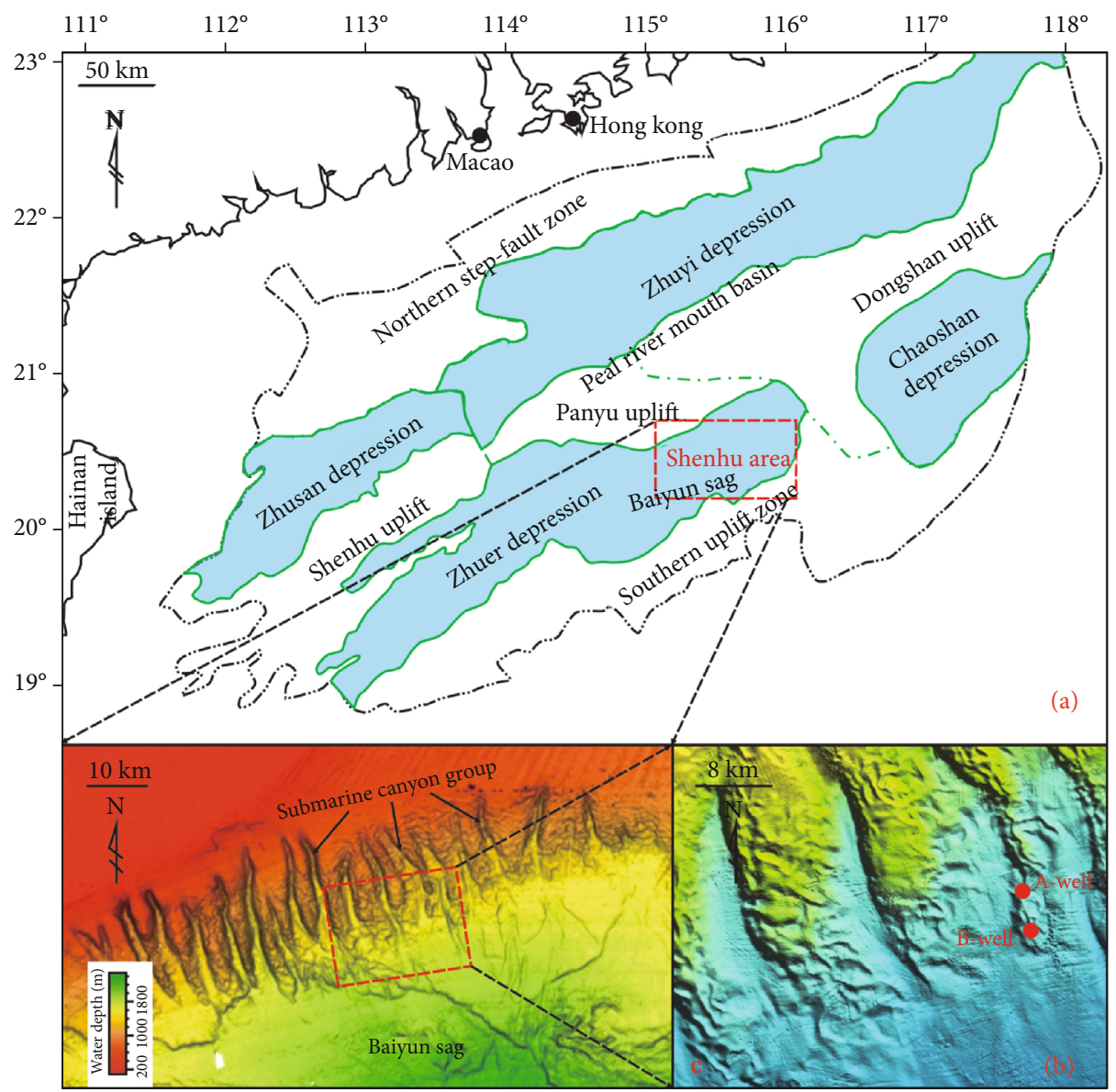

FIGURE 1: Regional geological background of the Shenhu area in the north of South China Sea.

Green Canyon in the Gulf of Mexico [31], the Blake Ridge in North America [32], and the Nankai Trough in Japan [33]. Researches on gas hydrate reservoirs in the Shenhu area, South China Sea, have systematically discussed the geological and geochemical characteristics of gas hydrate and associated free gas $[34,35]$.

Although the above studies infer the phenomenon and formation mechanism of gas hydrate and associated free gas, there is no detailed description of natural gas hydrate layer and associated free gas layer. Therefore, in this study, we use an accurate well-to-seismic calibration method to fine depict gas hydrate and free gas reservoirs and compare the differences between them, which lays a foundation for subsequent estimation of gas hydrate and free gas resources.

\section{Geological Setting}

The Shenhu area is geographically located in the northern slope area of the South China Sea and structurally situated in the Baiyun sag, Zhuer depression, and Peal River Mouth Basin (Figure 1(a)). Its seafloor topography is relatively flat, with an average slope of $3^{\circ}$. There are many types of landforms in the Shenhu area, including sea knolls, sea valleys, erosion slots, and gullies $[34,36]$. The water depth is between 1000 and $1700 \mathrm{mbsl}$, and the Shenhu area is divided into two parts, the north and south, with the water depth of $1350 \mathrm{mbsl}$ as the boundary (Figure 1(b)). In the north part, the terrain is relatively steep, and there are 17 nearly north-south trending submarine trenches from west to east, which are arranged alternately with seamounts. In the south part, the terrain is flat and gradually becomes abyssal plain to the south. The A-B ore body is taken as the interested object in this study, which is located in the submarine canyon systems in the northern slope of the Baiyun sag (Figure 1(c)). The A-well and B-well are situated at the top of the eastern ridges, with water depths of $1309.75 \mathrm{mbsl}$ and $1259.00 \mathrm{mbsl}$, total drilling depths of $222 \mathrm{mbsf}$ and $\sim 230 \mathrm{mbsf}$, and geothermal gradients of $5.46^{\circ} \mathrm{C} / 100 \mathrm{~m}$ and $4.43^{\circ} \mathrm{C} / 100 \mathrm{~m}$, respectively [3].

During the Cenozoic, the Pearl River Mouth Basin experienced several regional tectonic activities, including Shenhu movement, Zhuqiong movement, Nanhai movement, Baiyun movement, and Dongsha movement (Figure 2). The Cenozoic structural evolution of the Baiyun sag is characterized by two periods, i.e., rifting stage and depression stage. From the Paleocene to the early Oligocene, a halfgraben or graben depression was formed, with the continental strata of the Shenhu formation in the Paleocene, Wenchang formation in the Eocene, and Enping formation in the lower Oligocene deposited. In the late Oligocene, it became 


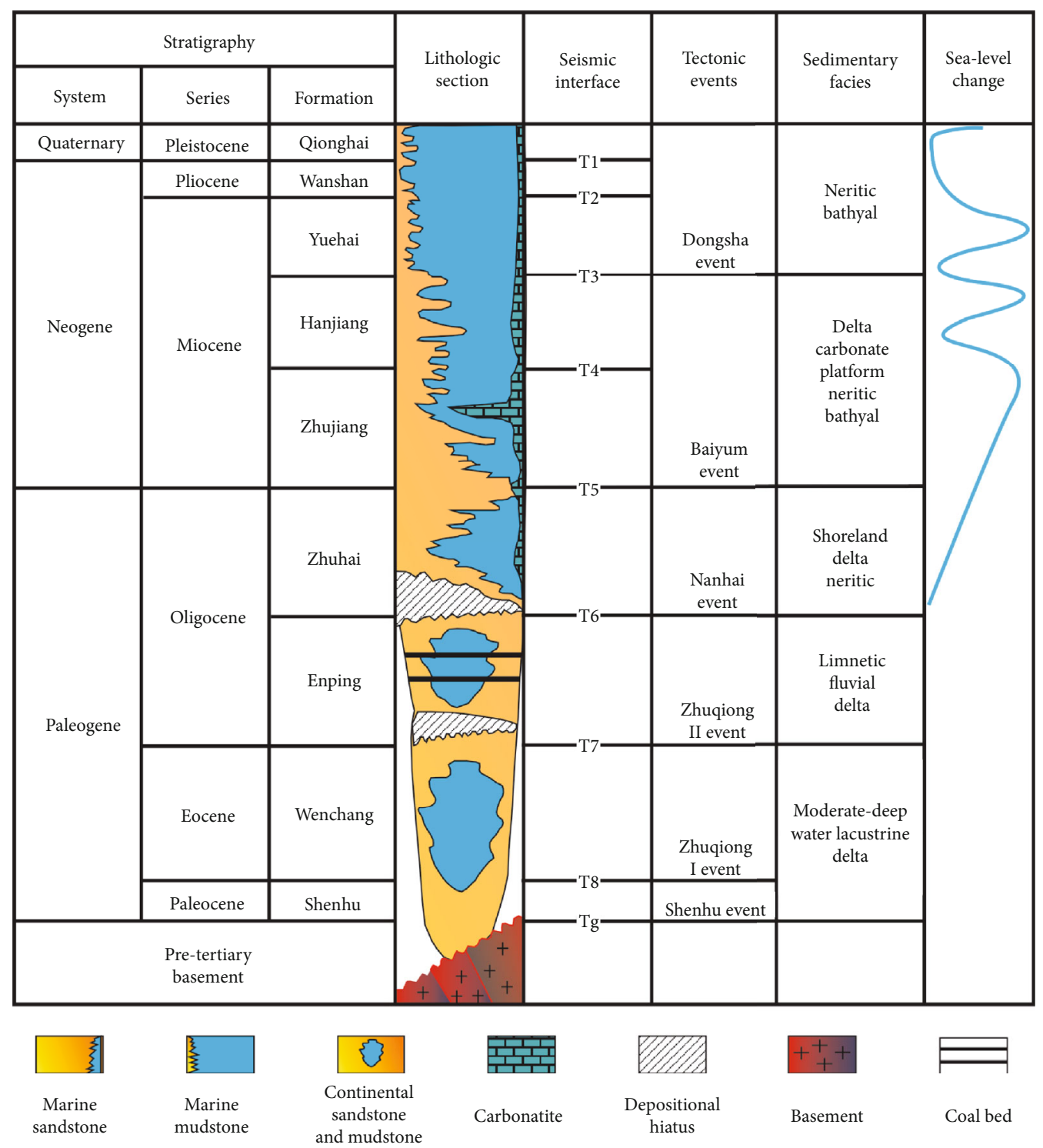

Figure 2: Comprehensive stratigraphic histogram of the Pearl River Mouth Basin.

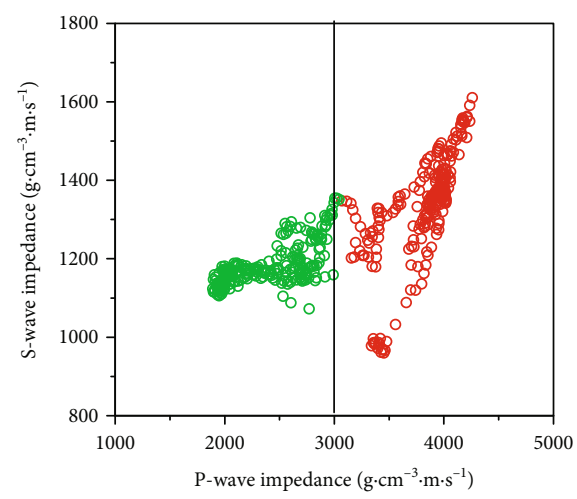

$\circ$ Gas hydrate - Free gas

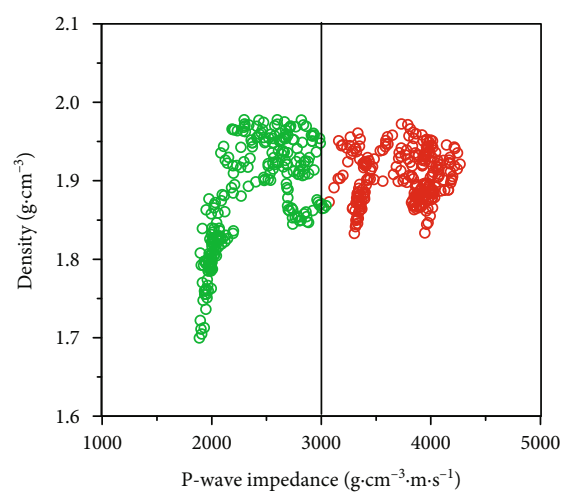

o Gas hydrate

o Free gas

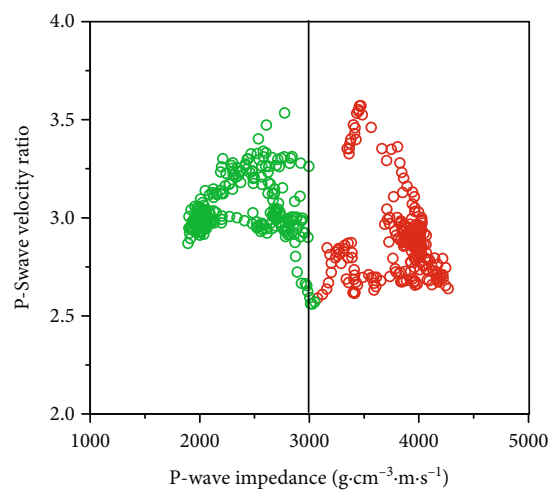

$\circ$ Gas hydrate

o Free gas

(c)

FIGURE 3: Intersection plate of different elastic parameters. 


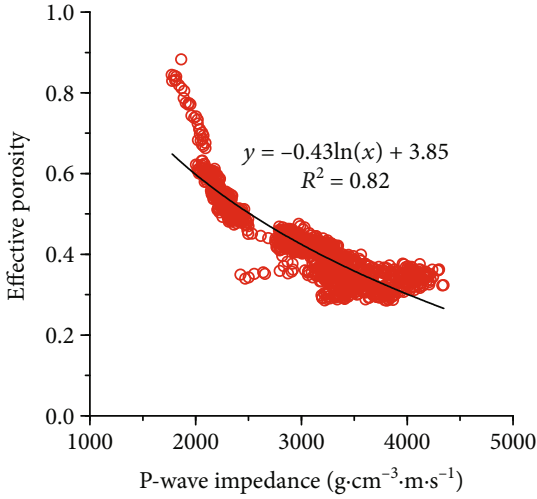

(a)

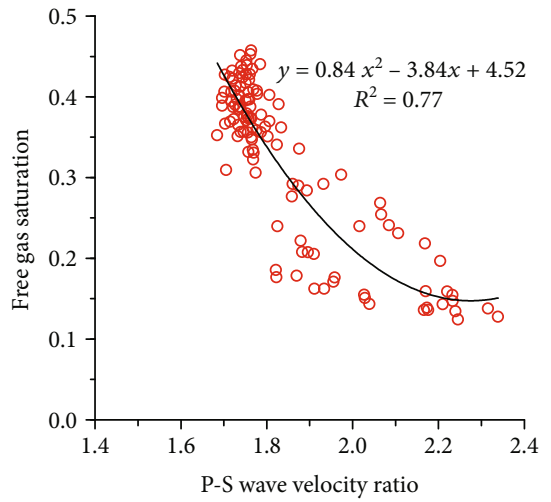

(b)

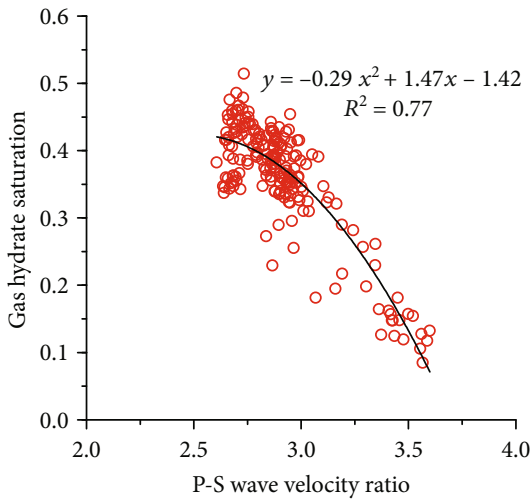

(c)

FIgURE 4: Correlation plate of physical properties and elastic parameters for gas hydrate and free gas.

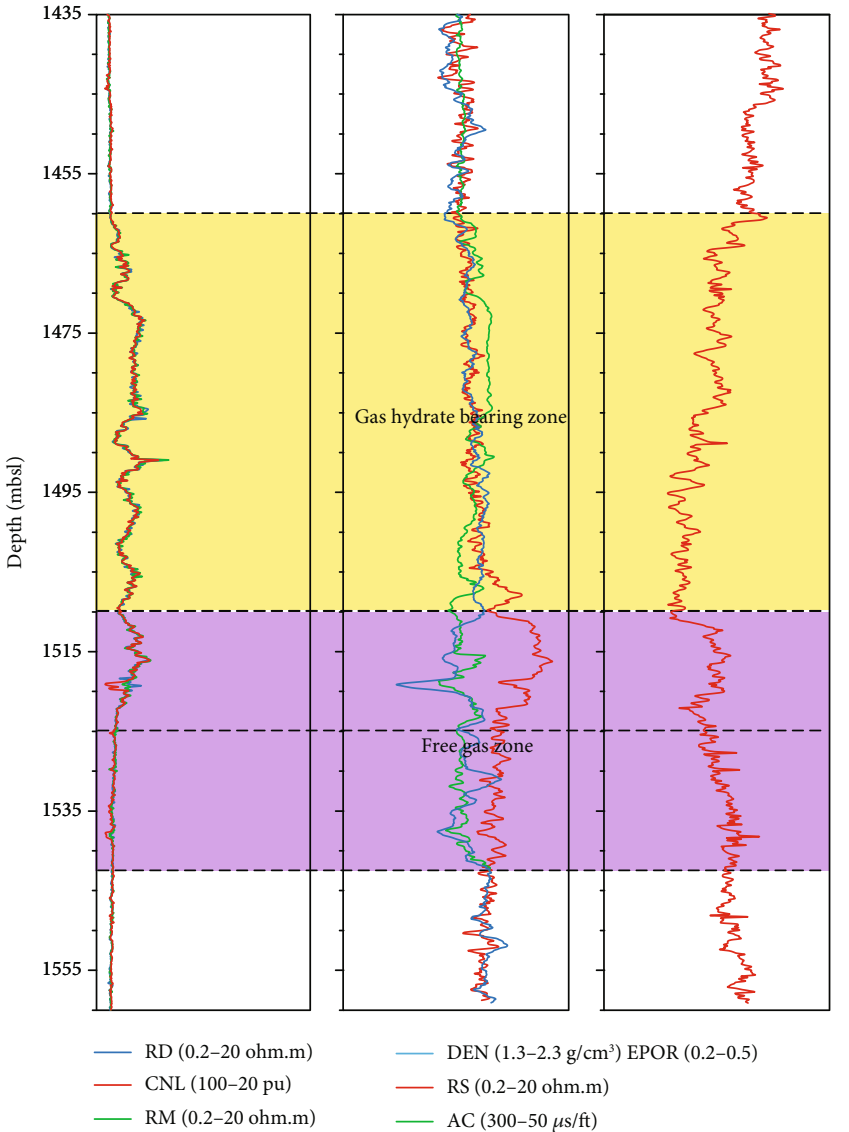

(a)

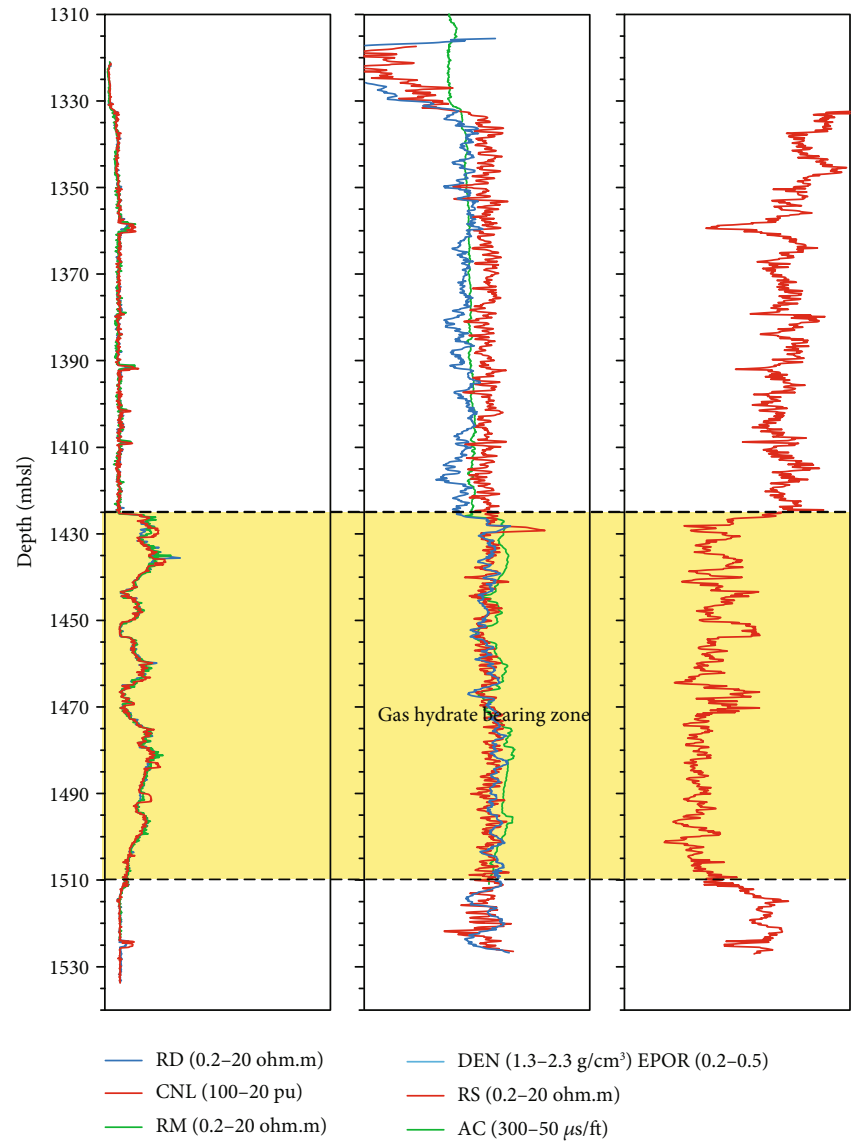

(b)

Figure 5: Comprehensive log interpretation graphs of the A-well and B-well.

a depression stage and deposited neritic facies strata of the Zhuhai formation. Subsequently, in the Miocene and Pliocene, it deposited neritic facies strata. There is an obvious unconformity between the lower Oligocene and the upper Oligocene. From the bottom to top, the Shenhu area develops successively continental facies, transitional facies, and marine facies strata, showing a trend of transgression [37].

\section{Methods}

3.1. Logging Identification Method of Natural Gas Hydrate and Free Gas. Logging response characteristics are the basis of identifying natural gas hydrate and free gas. Besides analyzing the response pattern of each logging curve, we adopt the curve overlap method to qualitatively identify natural 


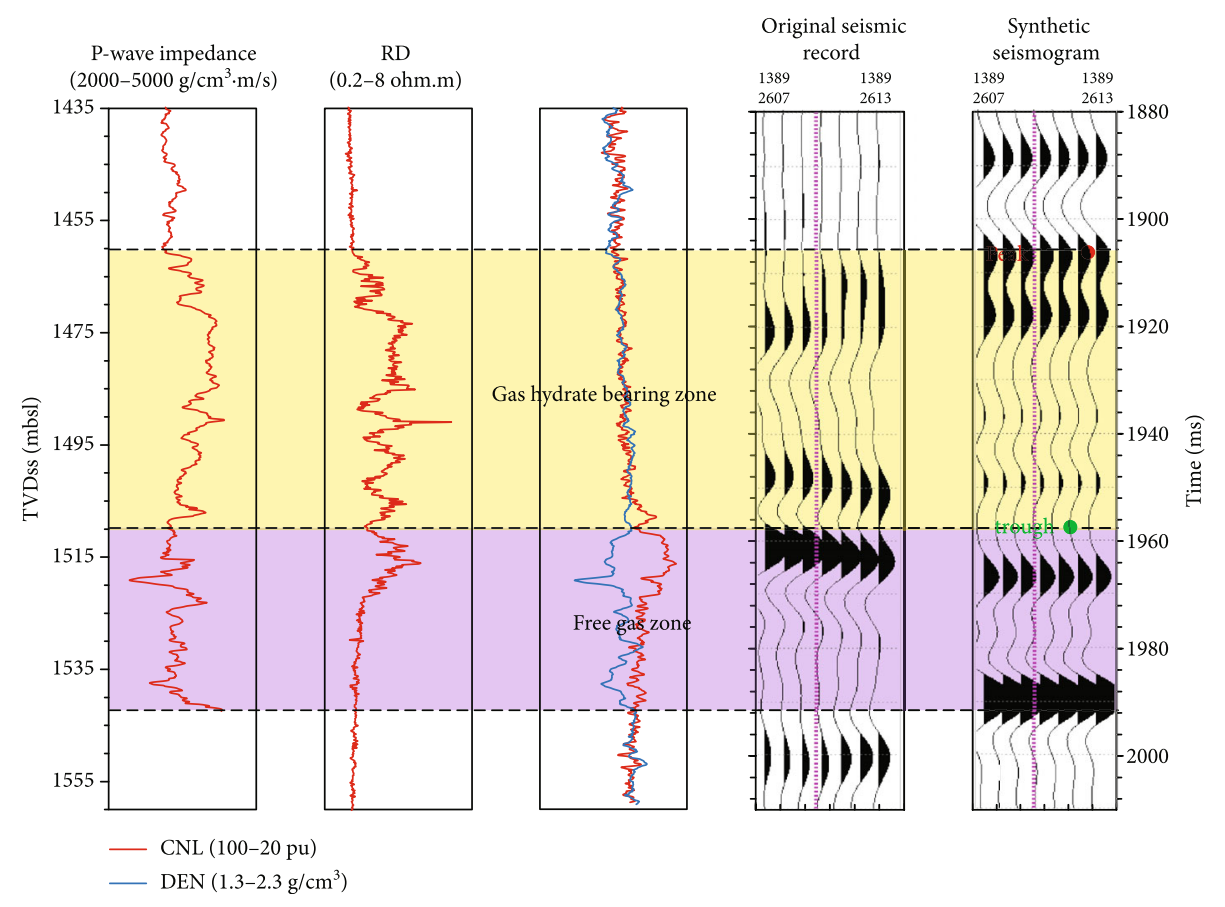

(a)

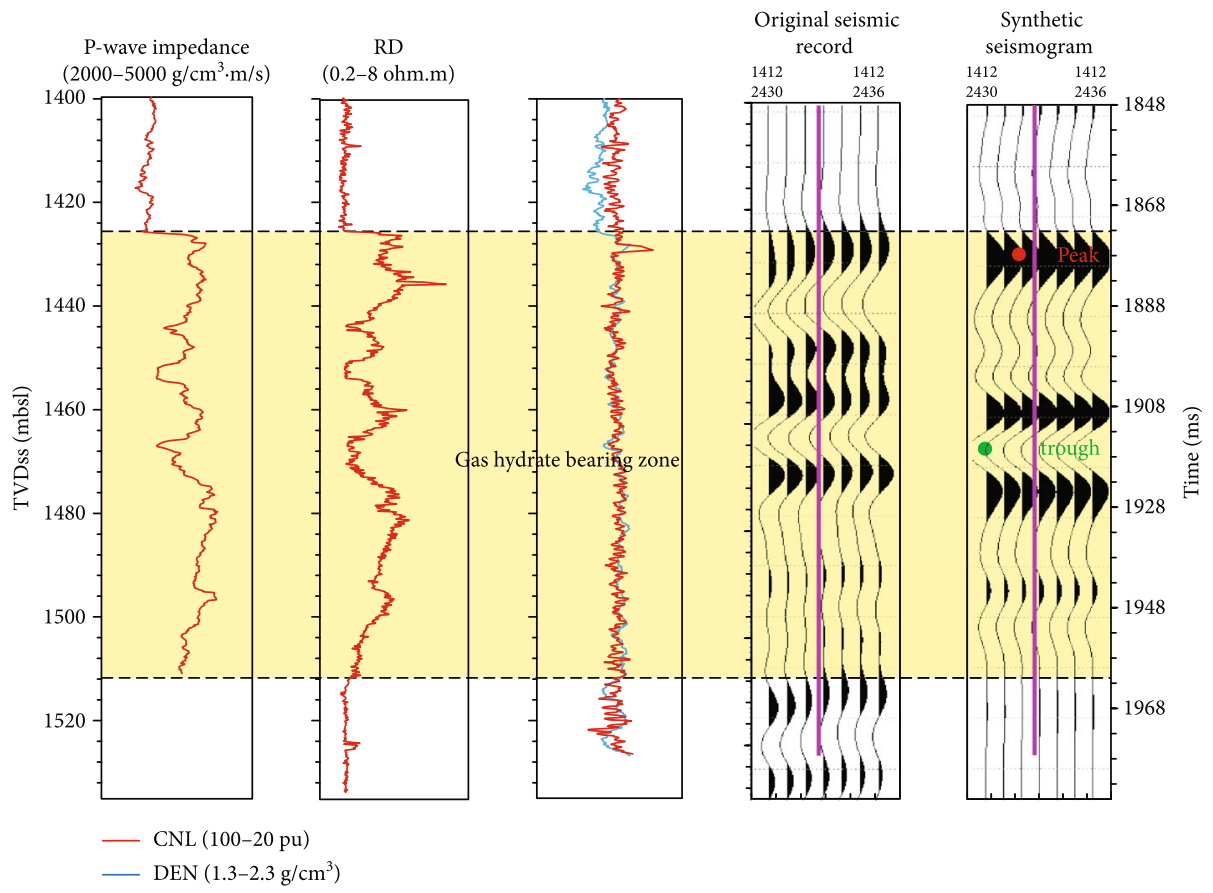

(b)

Figure 6: Logging curves and synthetic seismic records of the A-well and B-well.

gas hydrate and free gas. According to the overlap method, when gas was saturated in the reservoir, interval transit time increases, whereas density porosity and neutron porosity decrease. Through reasonable standardization, interval transit time and density porosity can overlap with neutron porosity in the water layer but separate in the gas layer [3].
3.2. Sensitivity Analysis of Gas Hydrate and Free Gas Elasticity Parameters. Elastic parameters are the link between well logging and seismic data, the sensitivity analysis of which is the basis of the seismic prediction method. Only when the elastic parameters of gas hydrate and free gas have a certain range, elastic inversion constrained by well logging is feasible [38]. 


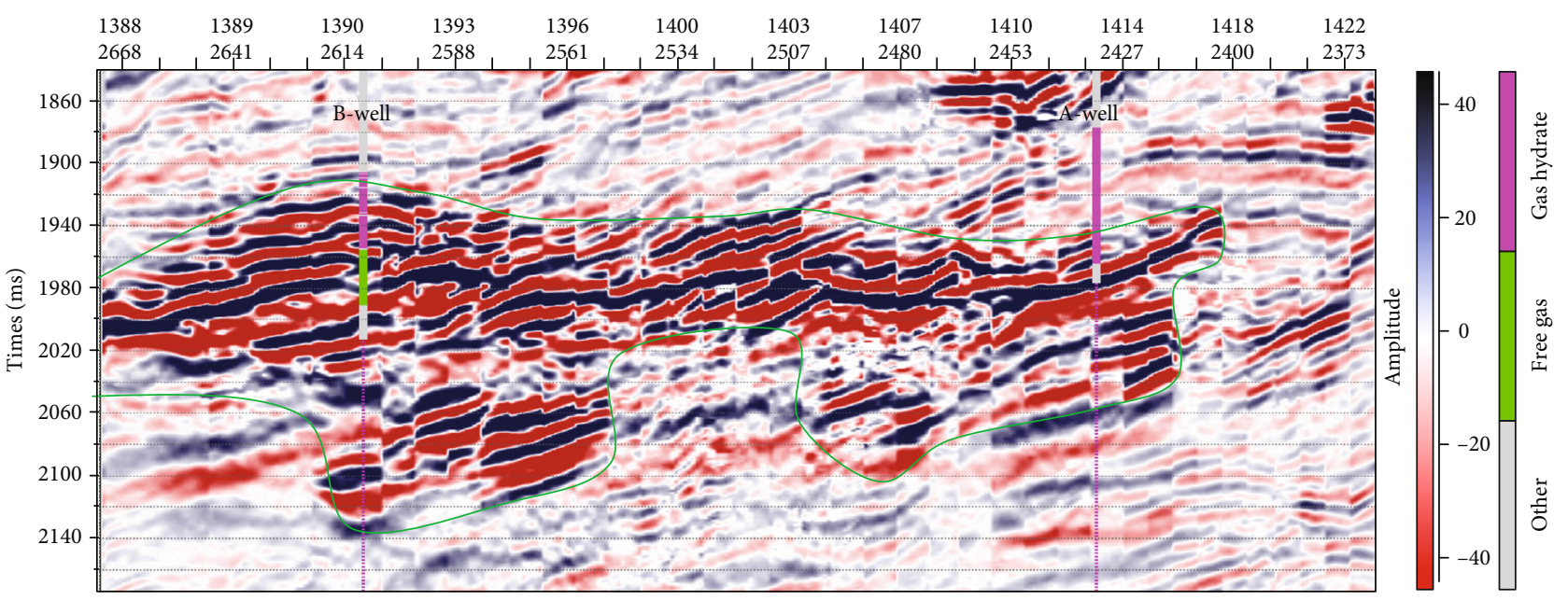

(a)

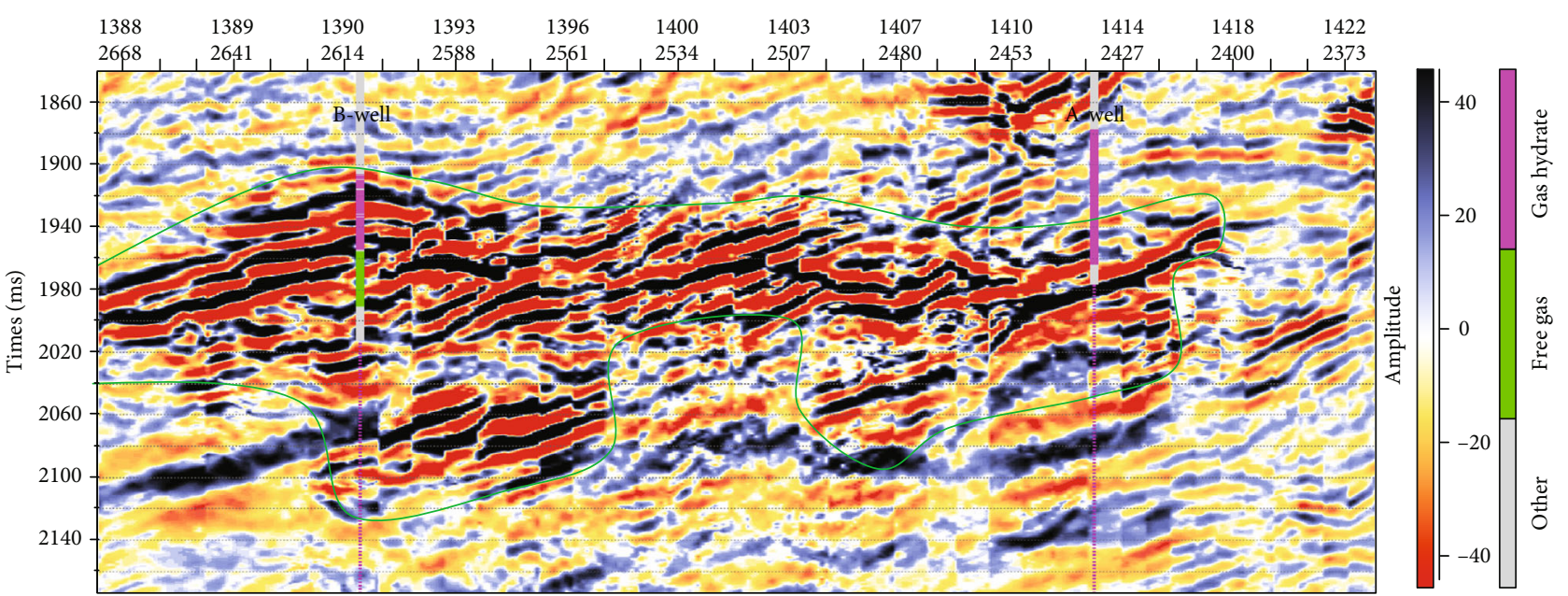

(b)

Figure 7: Well-tie AVO intercept and gradient cross section of the A-well and B-well: (a) AVO intercept; (b) AVO gradient.

Through the intersection analysis of different elastic parameters, it can be found that gas hydrate is characterized by high $P$-wave impedance $\left(P\right.$-imp $\left.>3000 \mathrm{~g} / \mathrm{cm}^{3} \cdot \mathrm{m} / \mathrm{s}\right)$, while free gas has an obvious characteristic of low $P$-wave impedance $\left(P\right.$-imp $\left.<3000 \mathrm{~g} / \mathrm{cm}^{3} \cdot \mathrm{m} / \mathrm{s}\right)$ (Figure 3$)$.

Therefore, $P$-wave impedance is one of the most sensitive elastic parameters for gas hydrate and free gas. Through $P$-wave impedance data, gas hydrate and free gas could be identified accurately.

There is a strong difference in $P$-wave impedance values between gas hydrate and free gas. Using the constrained sparse spike inversion (CSSI) method in the software Jason, under the control of the gas hydrate-bearing zone and bottom simulating reflector (BSR), the entire logging data for the hydrate ore body in the study area was used to complete the poststacking CSSI processing and obtain the $P$ -wave impedance, which revealed the distinct distribution of the GHBZ and underlying free gas. The top of gas hydrate is determined by strong amplitude reflection consistent with the polarity of the seafloor, and the bottom is identified by BSR.
3.3. Correlation Analysis of Physical Properties and Elasticity Parameters for Gas Hydrate and Free Gas. Through analyzing the correlation between physical properties and elasticity parameters of gas hydrate and free gas, it could be found that there is a good correlation between effective porosity and $P$ -wave impedance, whereas saturation and $P-S$ wave velocity ratio have a good relationship (Figure 4). The fitting relationship is as follows:

$$
\begin{aligned}
\text { Effective porosity }= & -0.43 \times \ln (P \text {-wave impedance }) \\
+ & 3.85\left(R^{2}=0.82\right), \\
\text { Free gas saturation }= & 0.84 \times(P \text {-S wave velocity ratio })^{2} \\
& -3.84 \times(P \text {-S wave velocity ratio }) \\
+ & 4.52\left(R^{2}=0.77\right), \\
\text { Gas hydrate saturation }= & -0.29 \times(P \text {-S wave velocity ratio })^{2} \\
& +1.47 \times(P \text {-S wave velocity ratio }) \\
& -1.42\left(R^{2}=0.77\right) .
\end{aligned}
$$




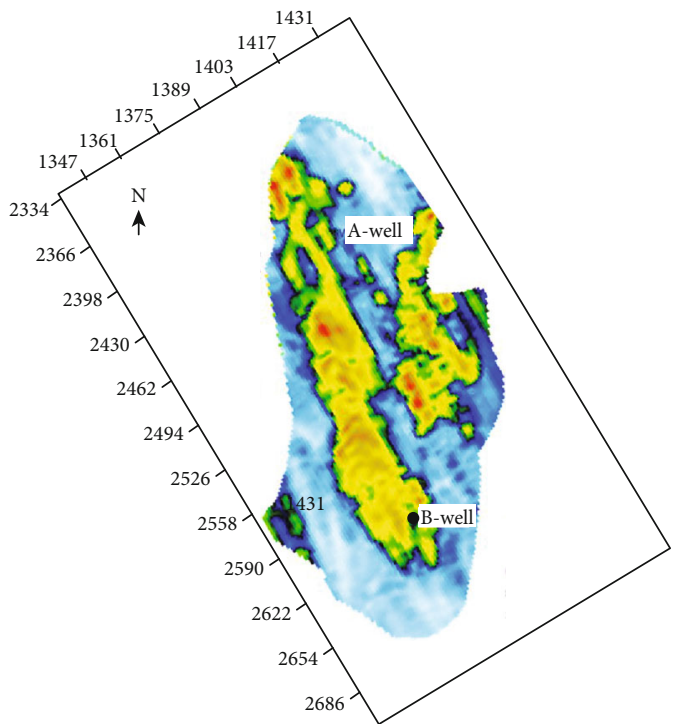

(a)

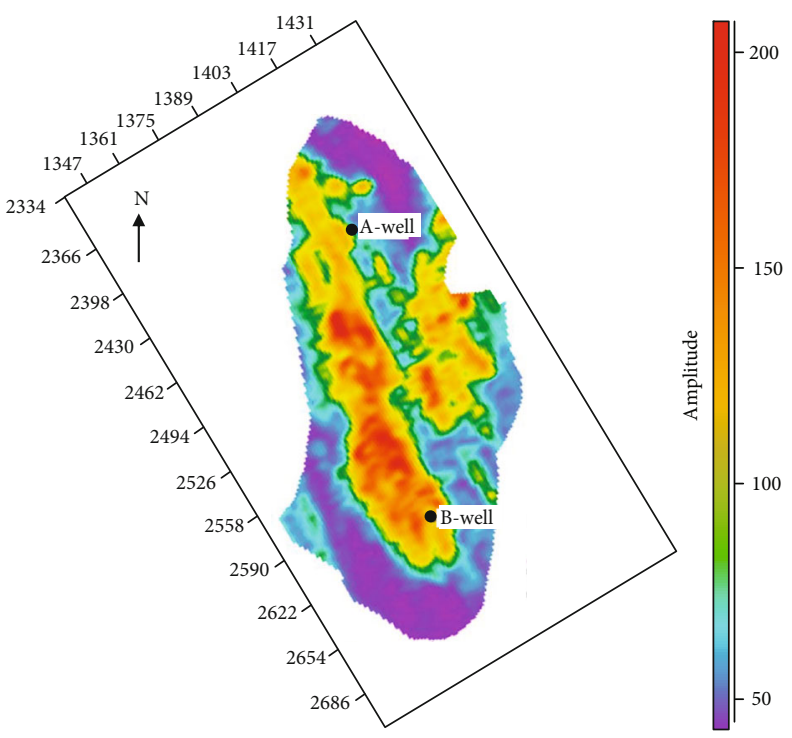

(c)

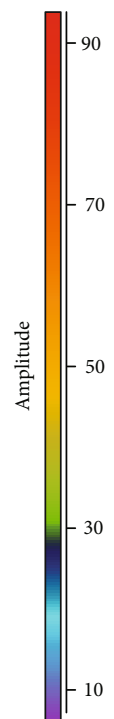

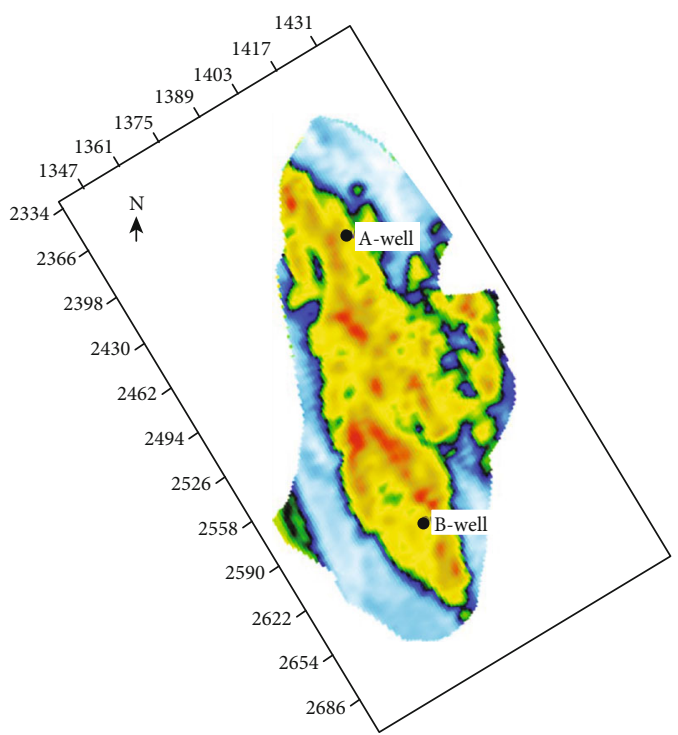

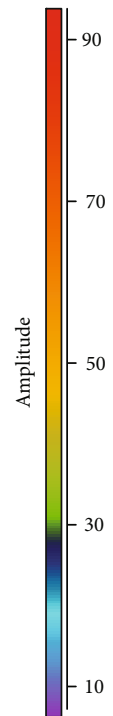

(b)
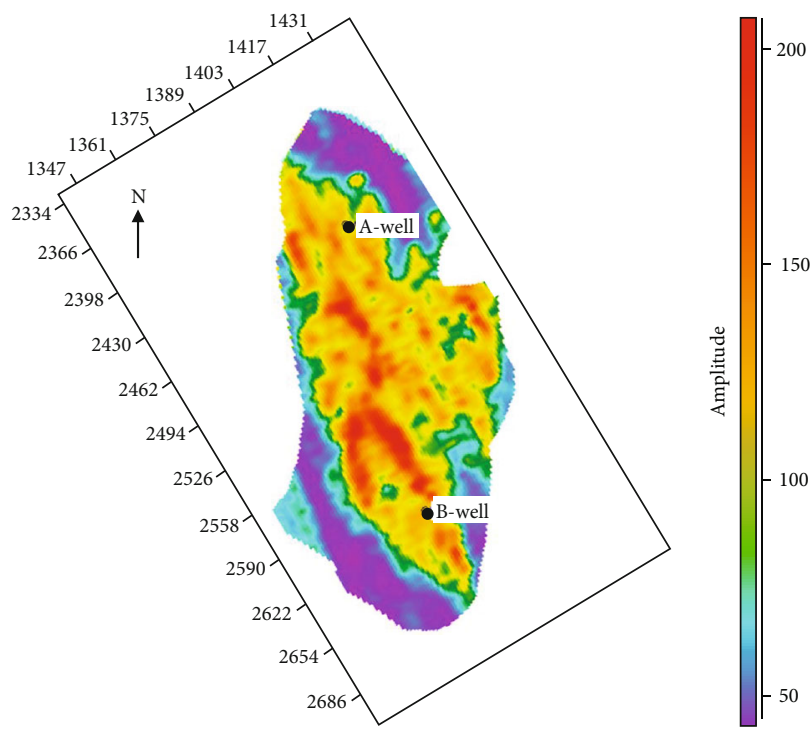

(d)

FIGURE 8: Root-mean-square attribute distribution of AVO intercept and gradient in the A-B ore body: (a) root-mean-square attribute of AVO intercept for gas hydrate; (b) root-mean-square attribute of AVO intercept for free gas; (c) root-mean-square attribute of AVO gradient for gas hydrate; (d) root-mean-square attribute of AVO gradient for free gas.

Using the above formulae, the spatial distribution of effective porosity, free gas saturation, and gas hydrate saturation of the A-B ore body could be well predicted based on the $P$-wave impedance and $P-S$ wave velocity ratio.

\section{Results}

4.1. Logging Interpretation of Gas Hydrate and Free Gas. Applying the overlap method to the A-well and B-well, it can be found that the resistivity curve of the B-well is characterized by high value in the depth of $1460-1525 \mathrm{mbsl}$ but medium value in the depth of 1525-1542 mbsl (Figure 5(a)). Its interval transit time, density porosity, and neutron porosity curves overlap each other in the depth of 1460-1510 mbsl but separate obviously in the depth of 1510-1542 mbsl. Thus, the depth range of $1460-1510 \mathrm{mbsl}$ in the B-well presents the response characteristics of gas hydrate, i.e., high resistivity and the overlap of interval transit time, density porosity, and neutron porosity. In contrast, in the 1510-1542 mbsl of the B-well, the response characteristics of free gas are characterized by medium-high resistivity, the separation of neutron porosity, and interval transit time with density porosity.

In addition, the depth range of 1425-1510 mbsl in the Awell shows the response characteristics of gas hydrate, i.e., high resistivity and the overlap of interval transit time, density porosity, and neutron porosity (Figure 5(b)). However, no obvious free gas is identified on the well logs of the Awell, perhaps due to limited logging depth. 


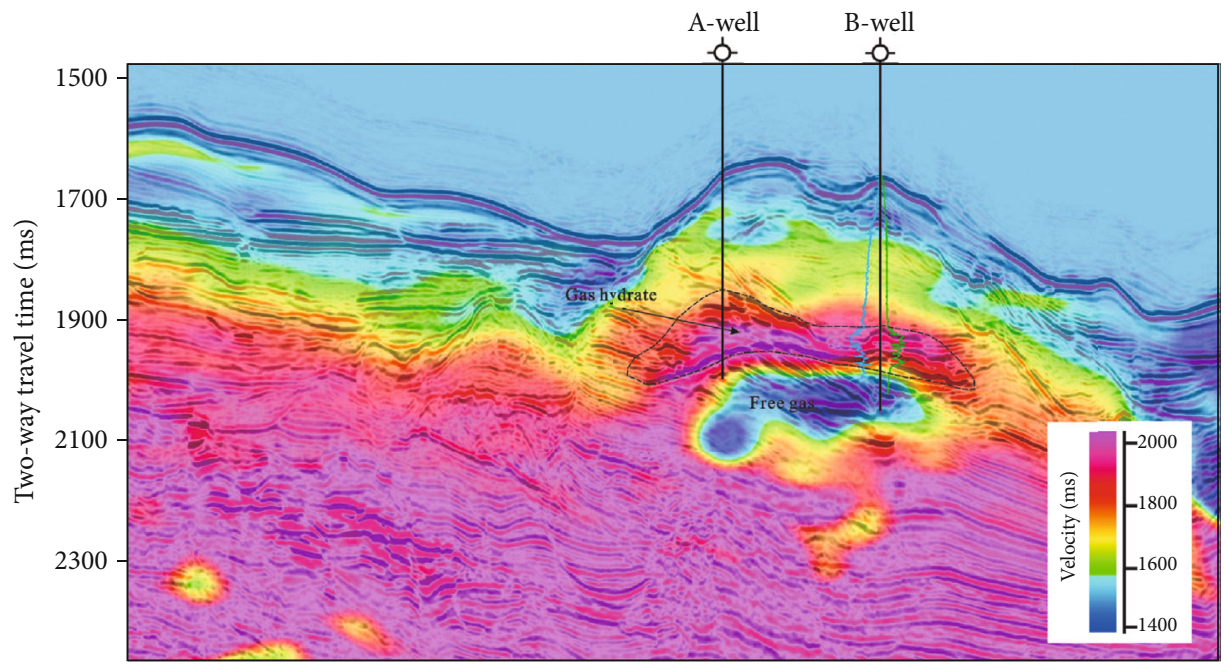

Figure 9: Well-tie P-wave velocity cross section of the A-well and B-well (according to [3]).

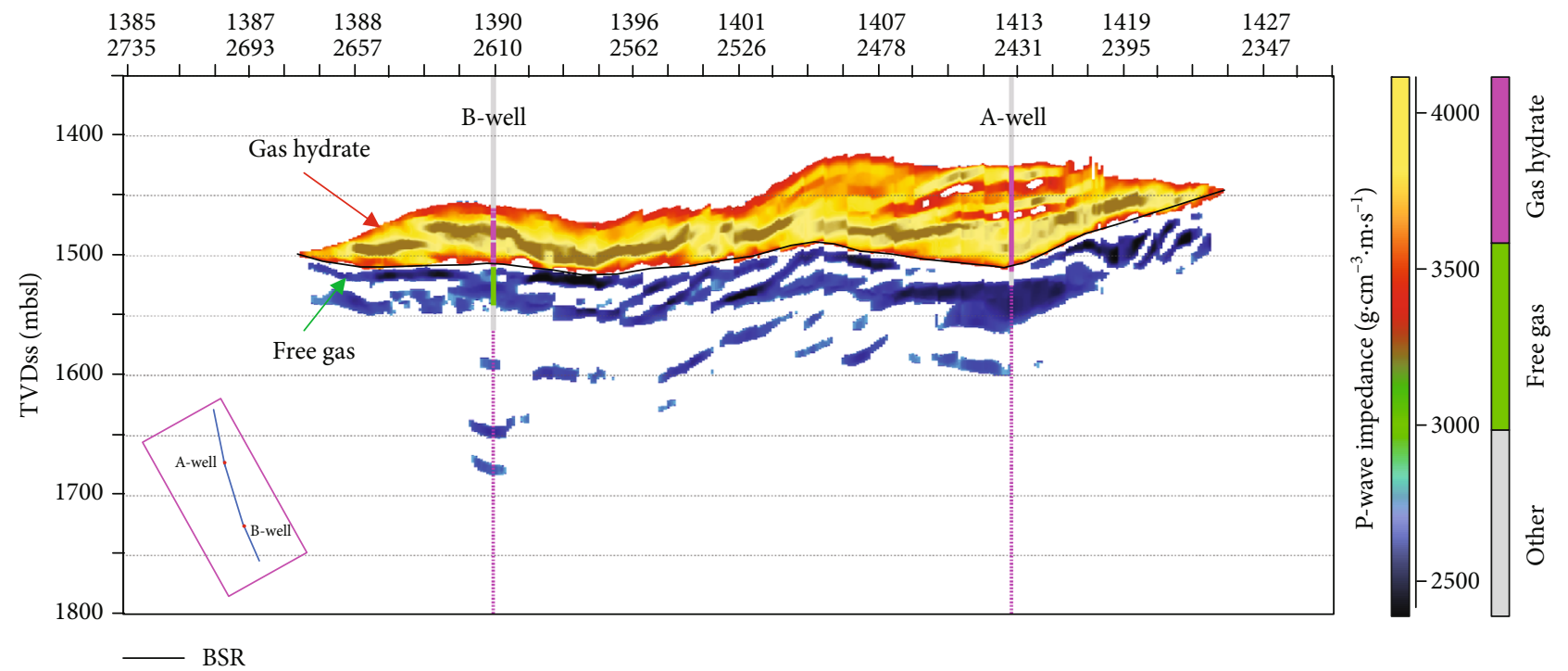

Figure 10: Well-tie $P$-wave impedance cross section of the A-well and B-well.

4.2. Seismic Reflection Characteristics of Gas Hydrate and Free Gas. According to logging curves and synthetic seismic records, it could be found that gas hydrate shows high P-wave impedance, and there is a positive reflection coefficient interface between the top of gas hydrate and the overlying strata with low $P$-wave impedance. In the seismic section, the corresponding seismic wave at the top of gas hydrate is characterized by strong wave peak, which indicates that the seismic section belongs to a normal polarity section. If the bottom of gas hydrate is in direct contact with the underlying free gas with low $P$-wave impedance, a negative reflection coefficient interface will appear, and the corresponding seismic wave in the seismic section will show a strong trough. On the contrary, if the bottom of gas hydrate does not contact with free gas directly, the reflection intensity of seismic wave is weak.

The top of gas hydrate in the B-well is characterized by strong wave peak, whereas the bottom shows strong wave trough, indicating that gas hydrate is in direct contact with free gas (Figure 6(a)). In addition, the top of gas hydrate in the A-well is characterized by strong wave peak, but the seismic wave amplitude at the bottom of gas hydrate is relatively weak (Figure 6(b)). It is shown that gas hydrate does not contact with free gas directly in the A-well, so a transition zone may exist between gas hydrate and free gas. Gas hydrates, free gas, and water coexist in the transition zone. The gas hydrates in this area are in a critically stable state and thus will dissociate once the temperature slightly increases or the pressure slightly decreases [39].

4.3. AVO Attribute Analysis of Gas Hydrate and Free Gas. According to well-to-seismic calibration, there are obvious anomaly areas in both intercept and gradient cross sections, showing a feature of bright points (Figure 7). In view of this feature, root-mean-square attribute values of intercept and gradient are extracted. The high-value areas represent the 


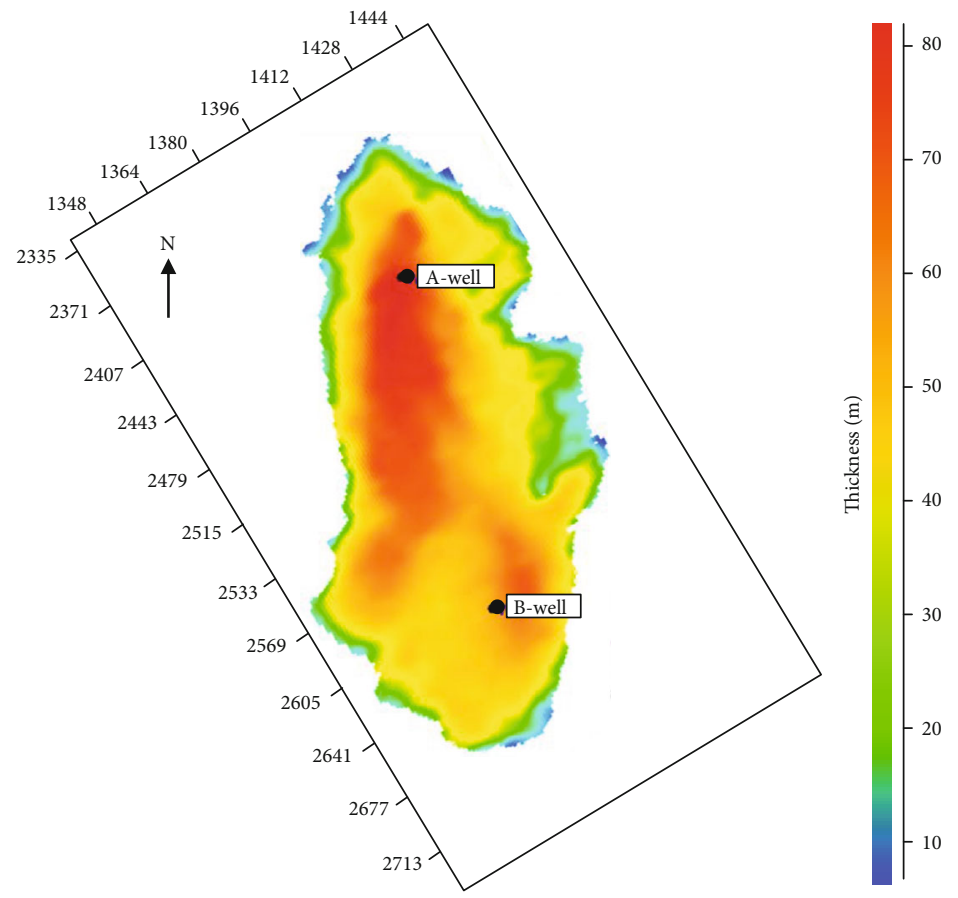

(a)

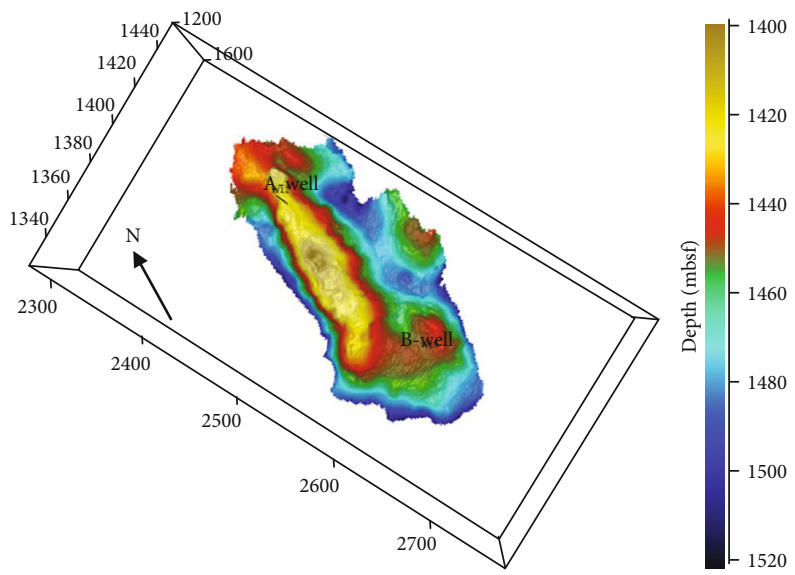

(b)

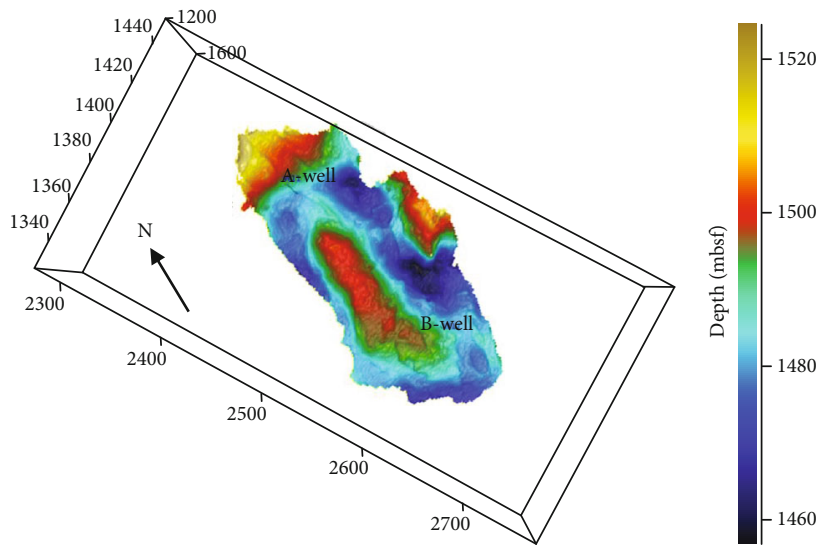

(c)

Figure 11: Thickness and spatial distribution of gas hydrate in the A-B ore body: (a) thickness distribution; (b) top surface structure; (c) bottom surface structure. 


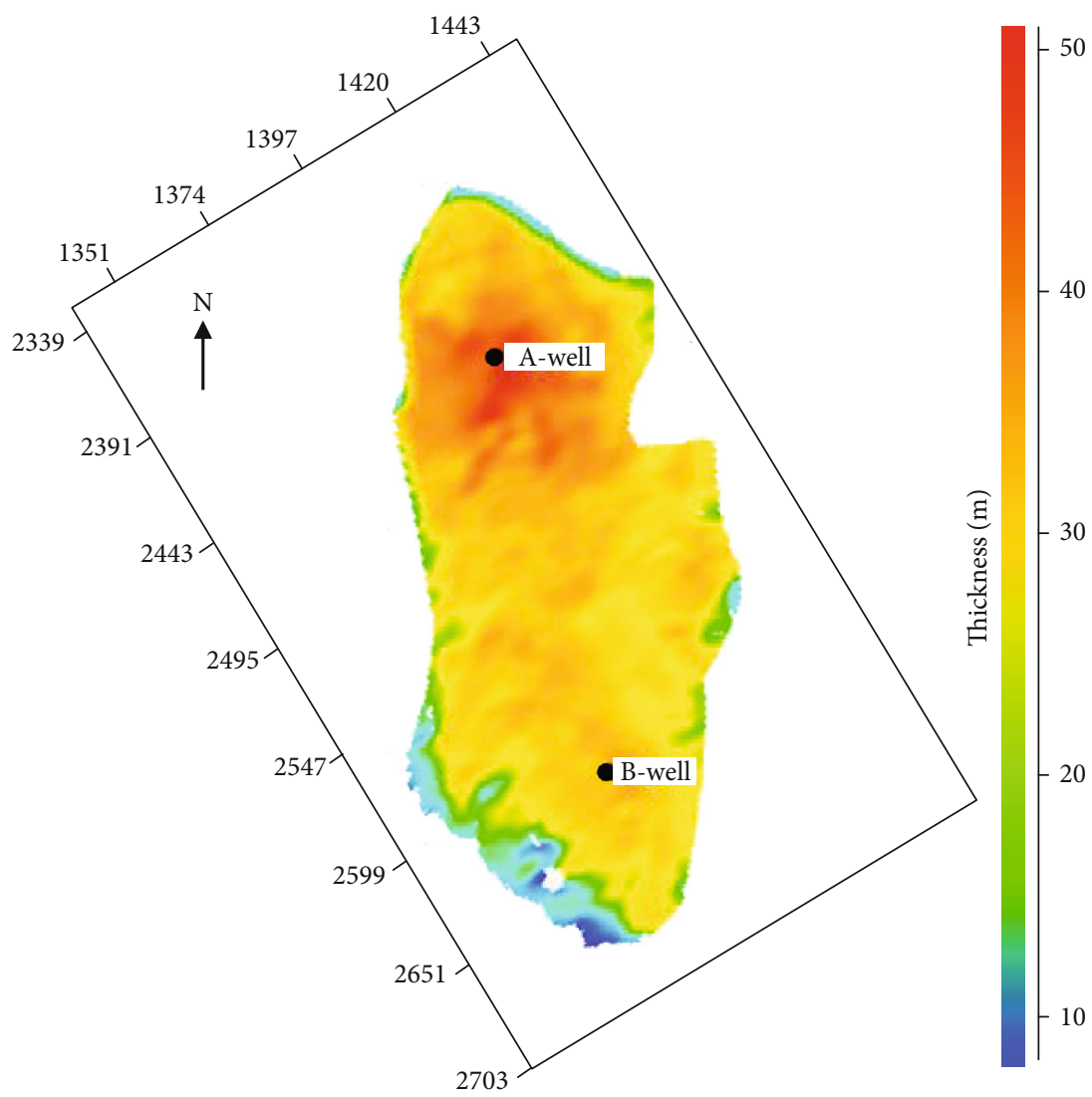

(a)

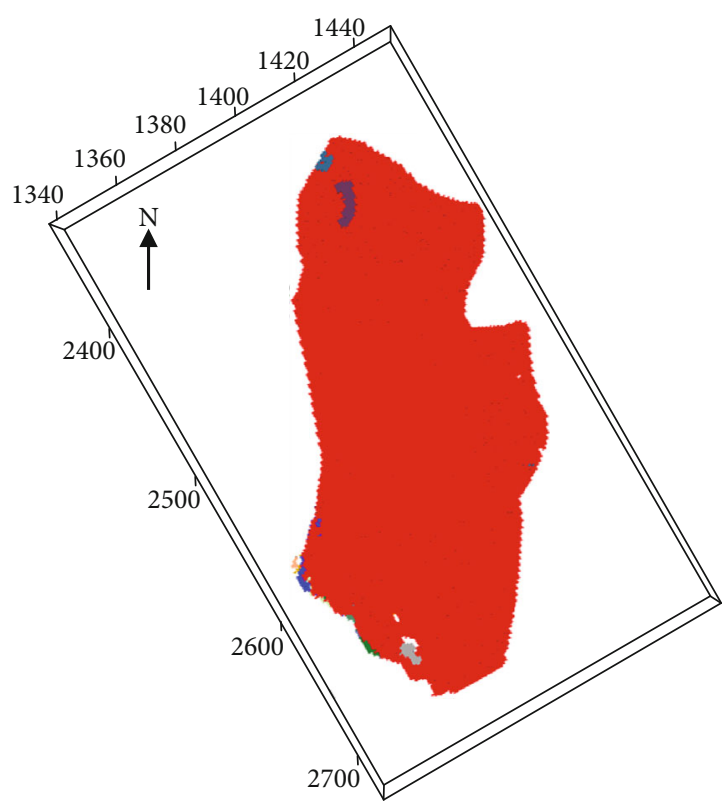

(b)

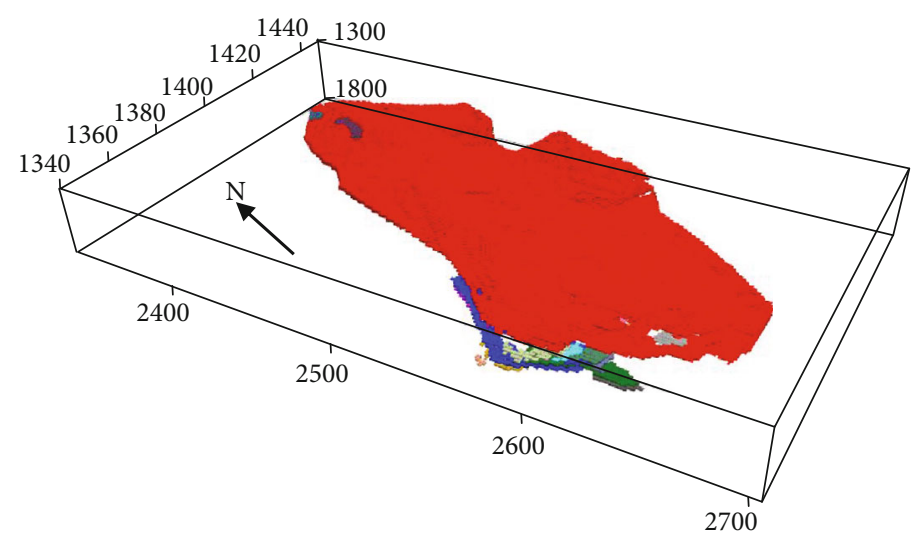

(c)

FIgURE 12: Thickness and spatial distribution of free gas in the A-B ore body: (a) thickness distribution; (b) top surface structure; (c) bottom surface structure.

favorable distribution zones of gas hydrate and free gas, which are nearly elliptical in the NW-SE direction (Figure 8).

\subsection{Seismic Inversion of Gas Hydrate and Free Gas}

4.4.1. P-wave Velocity. The well-tie $P$-wave velocity cross section of the A-well and B-well shows that gas hydrate possesses a high velocity of $1800-2000 \mathrm{~m} / \mathrm{s}$ (Figure 9). On the contrary, the underlying free gas has abnormal low velocity of $1400-1600 \mathrm{~m} / \mathrm{s}$. 


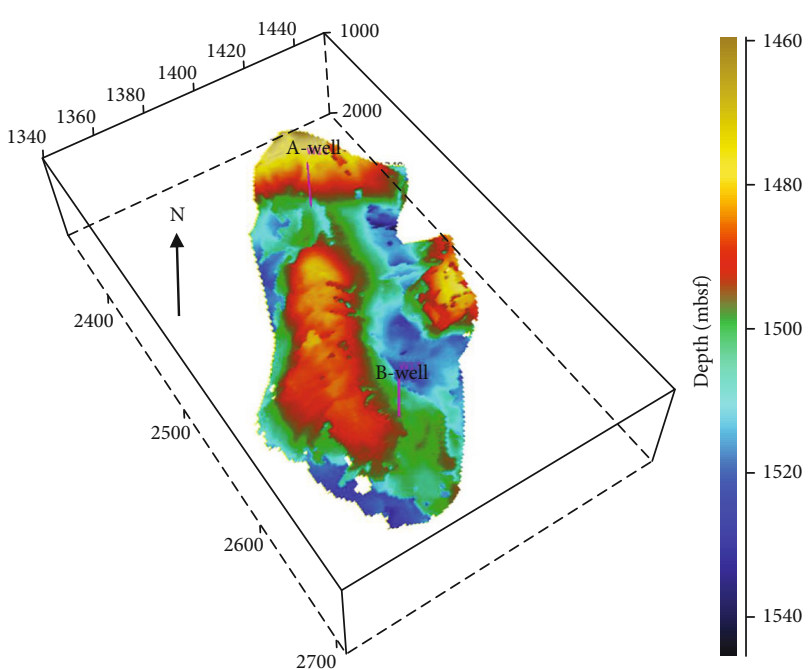

(a)

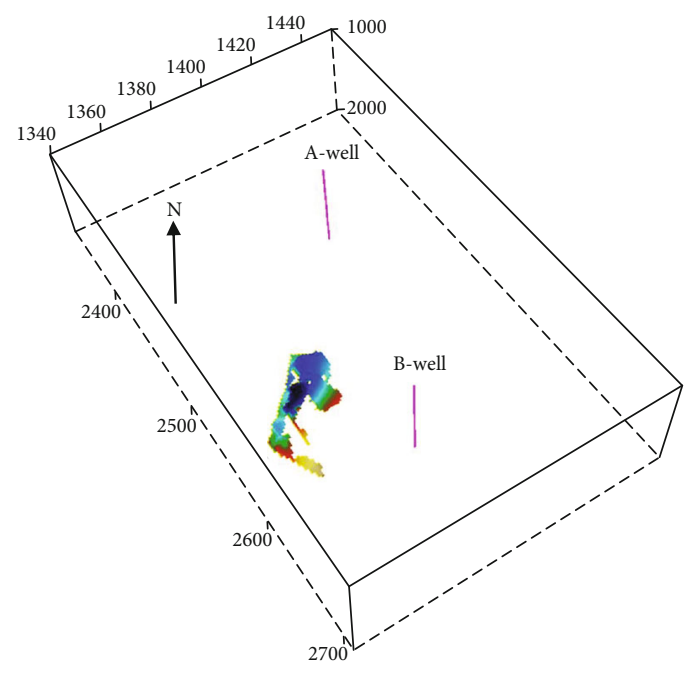

(c)

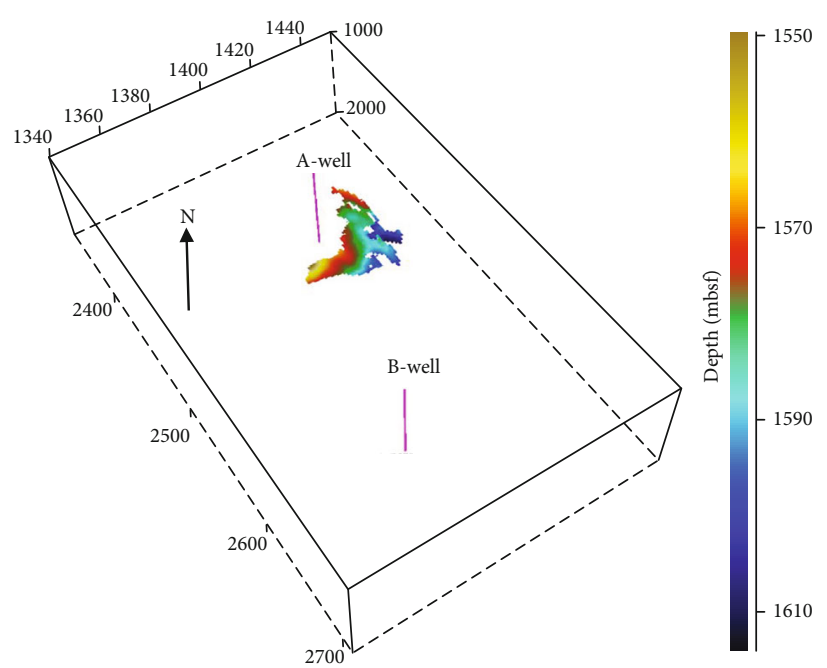

(b)
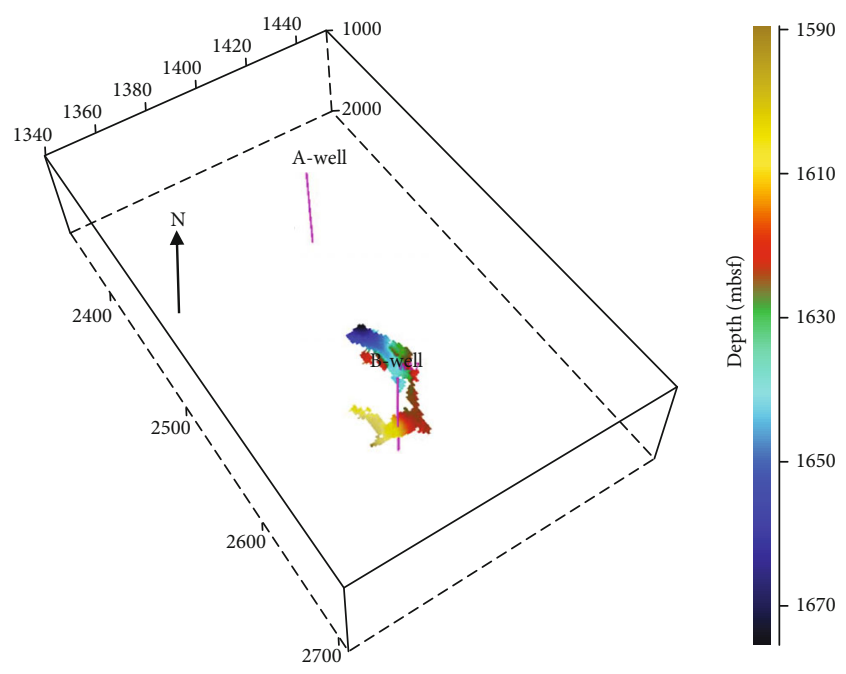

(d)

FIGURE 13: Three-dimensional spatial distribution of the main free gas reservoirs in the A-B ore body.

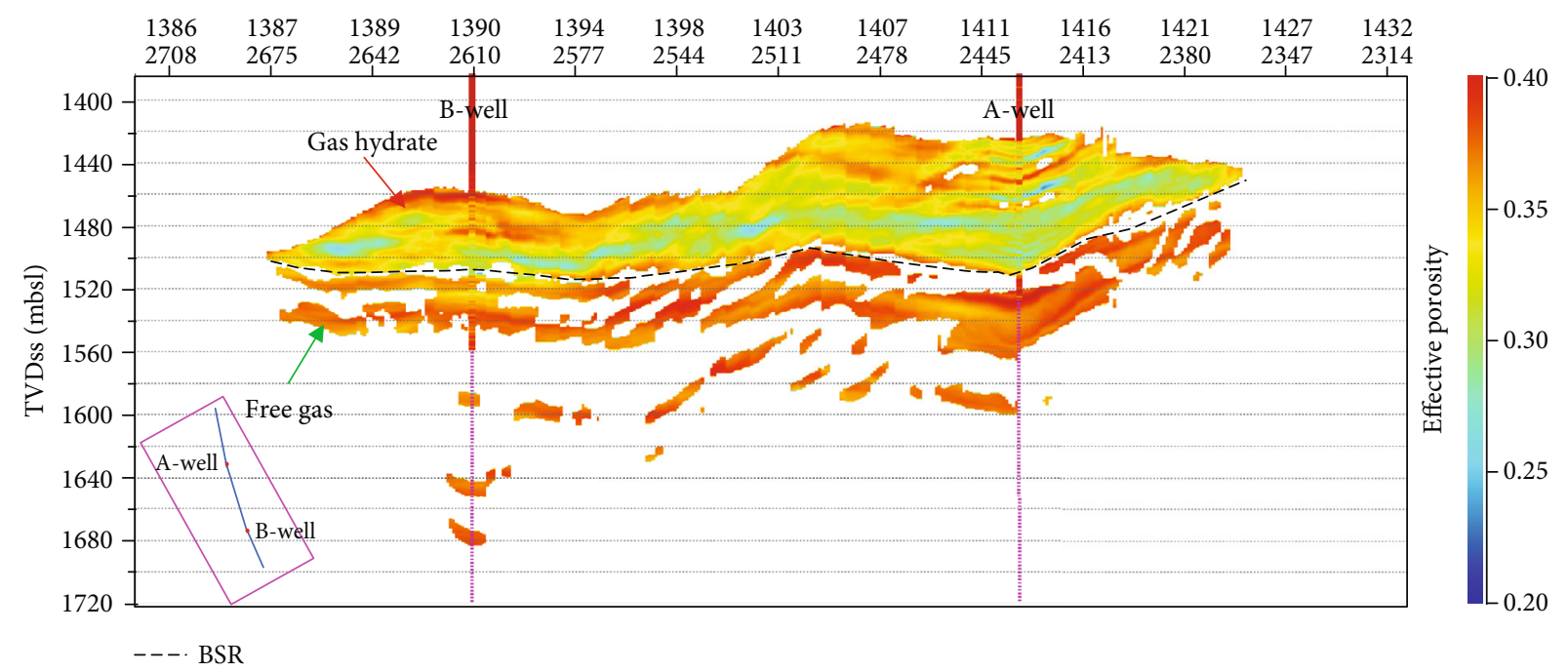

Figure 14: Well-tie effective porosity cross section of the A-well and B-well. 


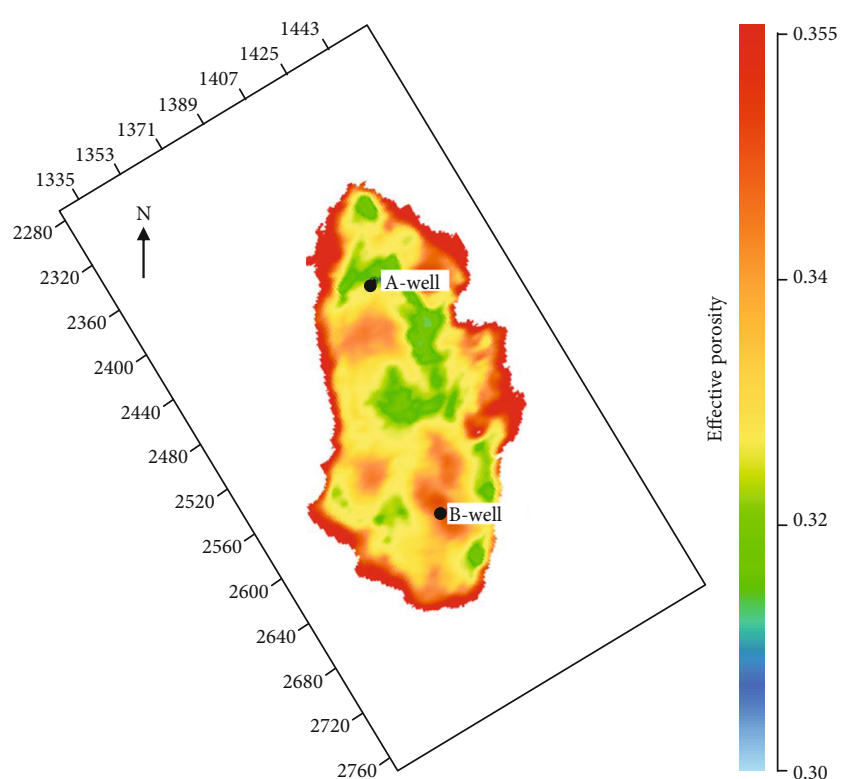

(a)

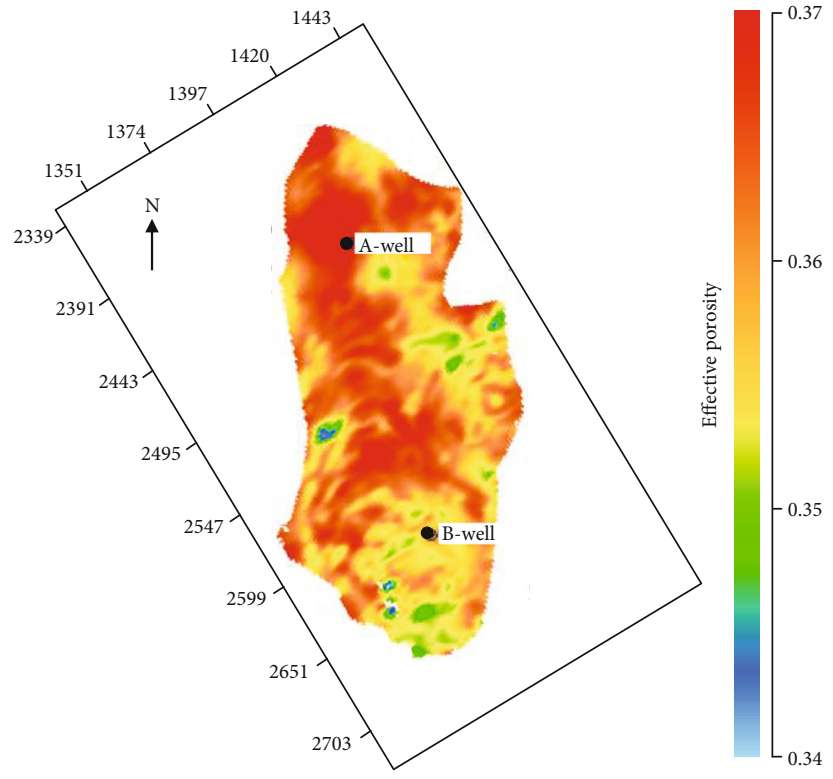

(b)

Figure 15: Plane distribution of effective porosity for gas hydrate and free gas in the A-B ore body.

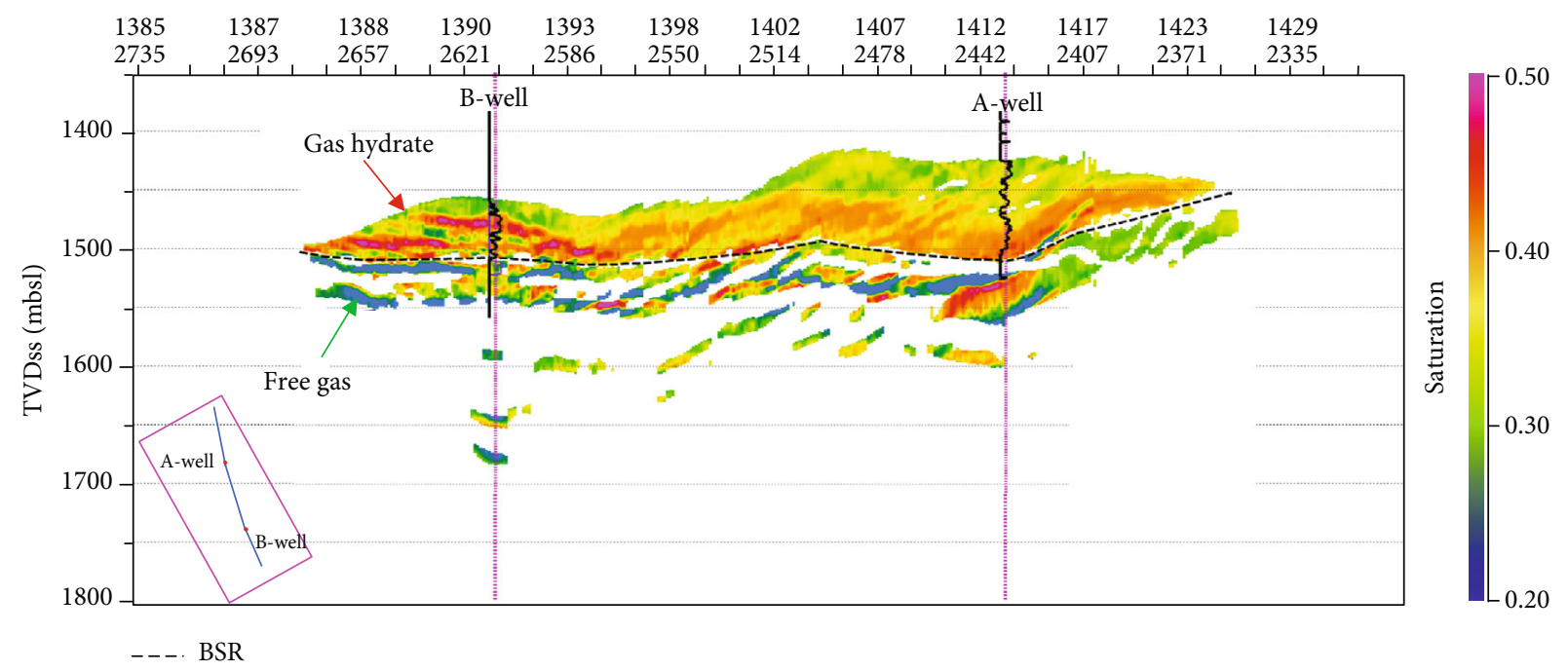

Figure 16: Well-tie saturation cross section of the A-well and B-well.

4.4.2. P-wave Impedance. According to seismic inversion, it could be found that gas hydrate is located above free gas and distributed continuously (Figure 10). The underlying free gas is especially enriched at the boundary of gas hydrate. The inversion results are in good agreement with the actual logging data, which just proves the previous interpretation of logging data.

4.4.3. Thickness and Spatial Distribution. Based on the distribution characteristics of $P$-wave impedance, gas hydrate and free gas are three-dimensionally carved to obtain the spatial distribution of the geologic body and calculate its thickness and volume. In plane form, gas hydrate shows nearly elliptical distribution in the NW-SE direction, and its thickness gradually thinned from the middle to the edge (Figure 11). Free gas has similar distribution characteristics with gas hydrate; that is, the distribution range, morphological feature, and thickness change are basically consistent with gas hydrate (Figure 12).

In space, three-dimensional carving technology is used to find out separate free gas reservoirs and quantitatively describe the surface structure, thickness, and volume of each free gas reservoir, so as to determine the most favorable free gas reservoir for exploitation. It is found that among all the free gas reservoirs, the free gas reservoir located directly below gas hydrate possesses the largest development scale, which is more than 40 times larger than other free gas reservoirs (Figure 13). 


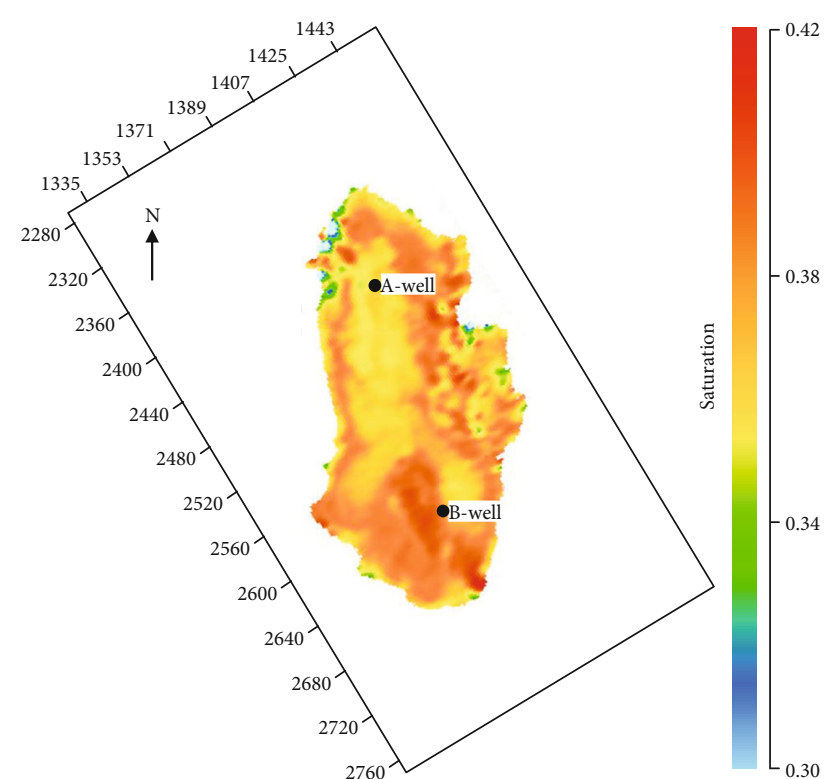

(a)

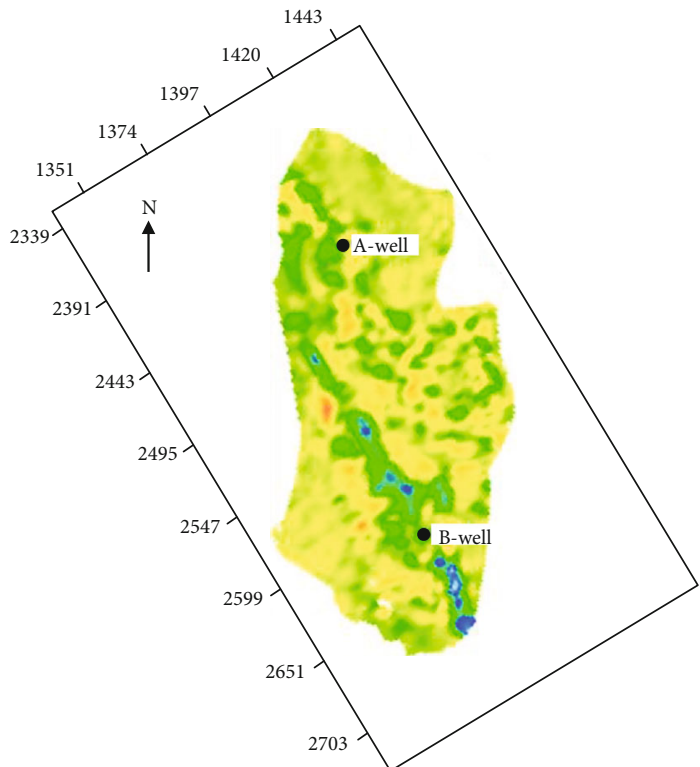

(b)

Figure 17: Plane distribution of average saturation for gas hydrate and free gas in the A-B ore body.

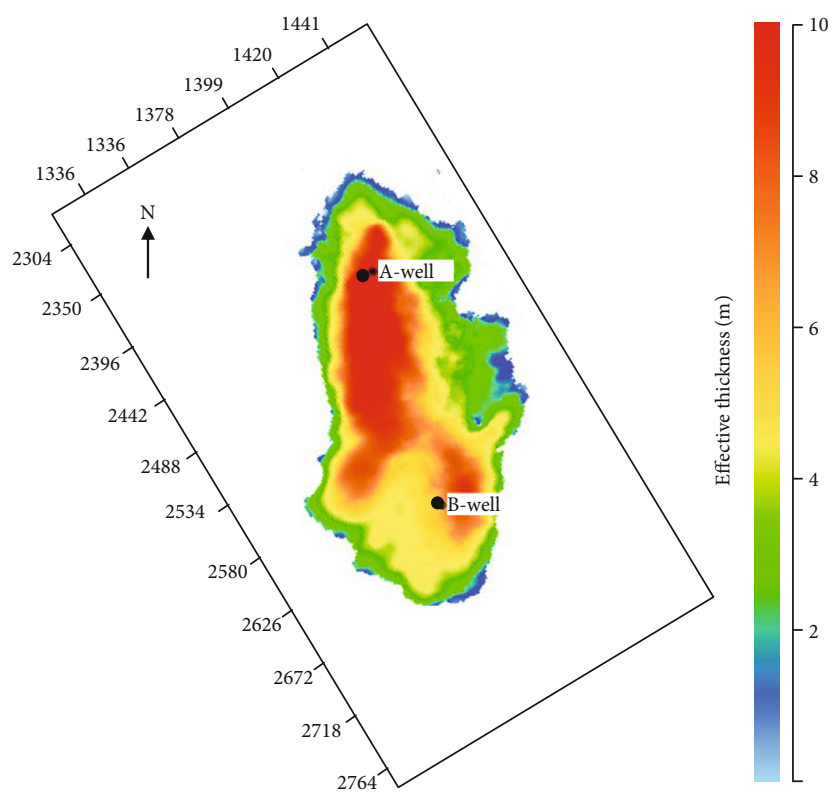

(a)

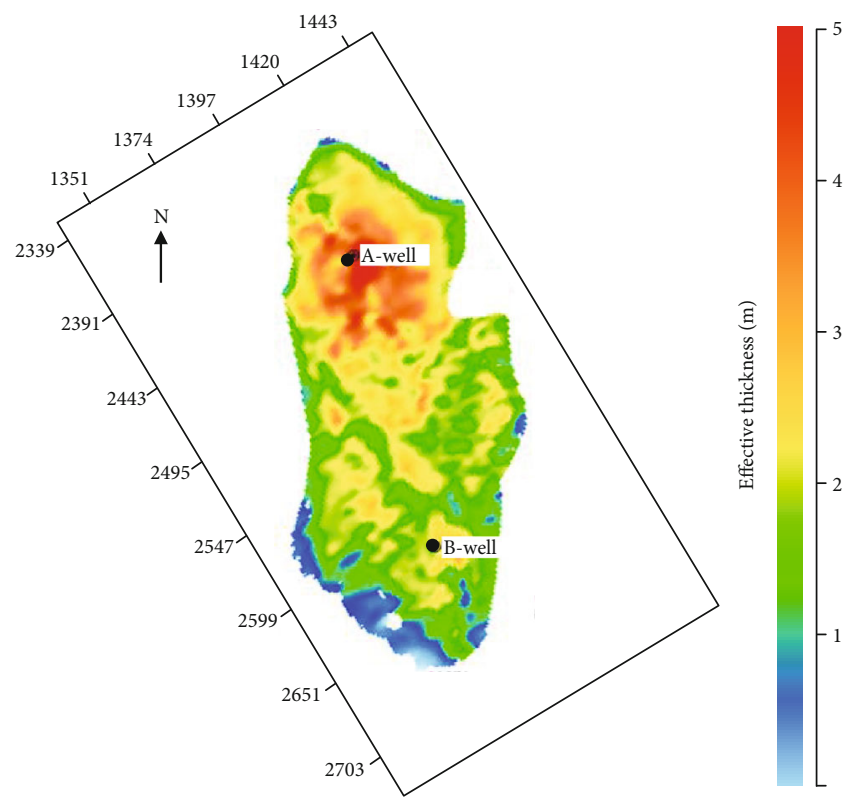

(b)

FIGURE 18: Plane distribution of average effective thickness for gas hydrate and free gas in the A-B ore body.

4.4.4. Effective Porosity. The effective porosity distribution of the $\mathrm{A}-\mathrm{B}$ ore body changes with $\mathrm{P}$-wave impedance. In the section, the effective porosity of gas hydrate is mainly between 0.30 and 0.40 , whereas the effective porosity of free gas is higher than that of gas hydrate, ranging from 0.35 to 0.40 and with small change and weak heterogeneity (Figure 14). These results are consistent with those predicted by logging interpretation (Figure 5).

In the plane, the effective porosity of gas hydrate is between 0.31 and 0.35 and increases from the middle to the surrounding, so it has obvious high value at the bound- ary of the A-B ore body (Figure 15(a)). In addition, the effective porosity of the B-well is higher than that of the A-well. On the whole, the effective porosity of free gas has little change in plane distribution, and its value is between 0.34 and 0.37 (Figure 15(b)). Different from gas hydrate, the effective porosity of free gas in the northern A-well area is slightly better than that in the southern B-well area.

4.4.5. Saturation. The saturation of the A-B ore body varies with the $P$-wave-to- $S$-wave velocity ratio. In the longitudinal section, the saturation of gas hydrate shows a trend of low 
value in the upper part and high value in the lower part, mainly in the range of $0.30-0.50$, while the free gas saturation is generally low, as low as 0.20 (Figure 16).

In the plane, the average saturation of gas hydrate is distributed in the range of $0.33-0.40$, with a small variation range (Figure 17(a)). The value of gas hydrate saturation in the southern B-well area is slightly larger than that in the northern A-well area. On the whole, the saturation of free gas is smaller than that of gas hydrate, which primarily ranges from 0.24 to 0.32 with little change (Figure $17(\mathrm{~b})$ ). There is a NW-trending low saturation zone through the B-well, which divides the A-B ore body into two distinct free gas area.

4.4.6. Average Effective Thickness. Based on the above study, the average effective thicknesses of gas hydrate and free gas could be calculated according to the thickness, effective porosity, and saturation. It can be seen in the plane that the average effective thicknesses are consistent with the trend of gas hydrate reservoir thicknesses (Figure 18). The average effective thicknesses in the north are better than those in the south, and the low values are primarily distributed at the boundary of the A-B ore body. The average effective thickness of gas hydrate primarily varies from $3.0 \mathrm{~m}$ to $10.5 \mathrm{~m}$ (Figure 18(a)), and that of free gas is mainly between $2.0 \mathrm{~m}$ and $5.0 \mathrm{~m}$ (Figure 18(b)).

\section{Conclusions}

Through evaluating the gas hydrate and free gas system of the A-B ore body in the Shenhu area, the following conclusions are obtained.

(1) According to logging interpretation, gas hydrate of the B-well is located in the depth range of 1460$1510 \mathrm{mbsl}$ and free gas is in 1510-1542 mbsl. Moreover, gas hydrate of the A-well is located in the depth range of 1425-1512 mbsl, and no obvious free gas is identified, due to limited logging depth

(2) Through the intersection analysis of elastic parameters, gas hydrate has the characteristics of high $P$ -wave impedance, while free gas is characterized by low $\mathrm{P}$-wave impedance. $P$-wave impedance is one of the most sensitive elastic parameters for gas hydrate and free gas

(3) Based on the correlation analysis of physical and elastic parameters, the effective porosity has a good correlation with $P$-wave impedance and so has saturation with the $P$-wave-to- $S$-wave velocity ratio. Therefore, according to the ratio of $P$-wave impedance and $P$-wave-to- $S$-wave velocity ratio, the effective porosity and saturation of hydrate and free gas can be calculated, finally predicting the spatial distribution of physical parameters

(4) According to logging curves and seismic synthetic record, gas hydrate in the B-well is in direct contact with free gas, while a transition zone may exist between gas hydrate and free gas in the A-well. According to well-to-seismic calibration, the anomaly areas of root-mean-square attribute values in intercept and gradient cross sections represent the favorable distribution zones of gas hydrate and free gas

(5) Gas hydrate has an effective porosity of $0.30-0.40$, an average saturation of $0.33-0.40$, and an effective thickness of $3.0-10.5 \mathrm{~m}$, whereas free gas possesses an effective porosity of $0.35-0.40$, a saturation of $0.24-0.32$, and an effective thickness of $2.0-5.0 \mathrm{~m}$

\section{Data Availability}

Data are available on request.

\section{Conflicts of Interest}

The authors declare that they have no conflicts of interest.

\section{Acknowledgments}

This work was supported by the China National Hydrate Project (DD20190224), Key Special Project for Introduced Talents Team of Southern Marine Science and Engineering Guangdong Laboratory (Guangzhou) (GML2019ZD0201), Guangdong Province Marine Economic Development (Six Major Marine Industries) Special Fund Project (No. Guangdong Natural Assets Cooperation [2021] No. 58), and the Open Fund Project of Hubei Key Laboratory of Marine Geological Resources (MGR202002).

\section{References}

[1] K. A. Kvenvolden, "Methane hydrate - a major reservoir of carbon in the shallow geosphere?," Chemical Geology, vol. 71, no. 1-3, pp. 41-51, 1988.

[2] K. A. Kvenvolden, "Gas hydrates-geological perspective and global change," Reviews of Geophysics, vol. 31, no. 2, pp. 173187, 1993.

[3] W. Zhang, J. Liang, J. Wei et al., "Geological and geophysical features of and controls on occurrence and accumulation of gas hydrates in the first offshore gas-hydrate production test region in the Shenhu area, northern South China Ssea," Marine and Petroleum Geology, vol. 114, article 104191, 2020.

[4] R. Boswell, T. S. Collett, M. Frye, W. Shedd, D. R. McConnell, and D. Shelander, "Subsurface gas hydrates in the northern Gulf of Mexico," Marine and Petroleum Geology, vol. 34, no. 1, pp. 4-30, 2012.

[5] T. S. Collett, "Energy resource potential of natural gas hydrates," AAPG Bulletin, vol. 86, no. 11, pp. 1971-1992, 2002.

[6] T. S. Collett, "Gas hydrates as a future energy resource," Geotimes, vol. 49, pp. 24-27, 2004.

[7] B. J. Anderson, M. Kurihara, M. D. White et al., "Regional long-term production modeling from a single well test, Mount Elbert Gas Hydrate Stratigraphic Test Well, Alaska North Slope," Marine and Petroleum Geology, vol. 28, no. 2, pp. 493-501, 2011.

[8] T. S. Collett, R. Boswell, J. R. Cochran et al., "Geologic implications of gas hydrates in the offshore of India: results of the 
National Gas Hydrate Program Expedition 01," Marine and Petroleum Geology, vol. 58, pp. 3-28, 2014.

[9] T. S. Collett, M. W. Lee, M. V. Zyrianova et al., "Gulf of Mexico Gas Hydrate Joint Industry Project Leg II logging-while- drilling data acquisition and analysis," Marine and Petroleum Geology, vol. 34, no. 1, pp. 41-61, 2012.

[10] S. R. Dallimore, "Summary and implications of the Mallik 2002 Gas Hydrate Production Research Well Program, Mackenzie Delta, Northwest Territories, Canada," pp. 1-36, 2005.

[11] G. J. Moridis, T. S. Collett, S. R. Dallimore, T. Satoh, S. Hancock, and B. Weatherill, "Numerical studies of gas production from several $\mathrm{CH}_{4}$ hydrate zones at the Mallik site, Mackenzie Delta, Canada," Journal of Petroleum Science and Engineering, vol. 43, no. 3-4, pp. 219-238, 2004.

[12] B. J. Ryu, T. S. Collett, M. Riedel et al., "Scientific results of the second gas hydrate drilling expedition in the Ulleung Basin (UBGH2)," Marine and Petroleum Geology, vol. 47, pp. 1-20, 2013.

[13] A. M. Tréhu, G. Bohrmann, and F. R. Rack, "Expedition 204 scientists," in Proceedings of the Ocean Drilling Program: Volume 204 Initial Reports, Drilling Gas Hydrates on Hydrate Ridge, Cascadia Continental Margin, Washington, DC, 2004.

[14] D. Panfeng, F. Yang, and Y. Cheng, "Research status and prospect of combustible ice," Contemporary Chemical Industry, vol. 48, no. 4, pp. 815-818, 2019.

[15] L. Yushan, Y. Zhu, and B. Wu, "Recent status of marine gas hydrate exploration and production," Marine Geology Frontiers, vol. 29, no. 6, pp. 23-31, 2013.

[16] Z. Caineng, Z. Guangming, Z. Guangya et al., "Formation, distribution, potential and prediction of global conventional and unconventional hydrocarbon resources," Petroleum Exploration and Development, vol. 42, no. 1, pp. 13-25, 2015.

[17] Z. B. Sha, J. Q. Liang, G. X. Zhang et al., “A seepage gas hydrate system in northern South China Sea: seismic and well log interpretations," Marine Geology, vol. 366, pp. 69-78, 2015.

[18] S. H. Wang, W. Yan, and H. B. Song, "Mapping the thickness of the gas hydrate stability zone in the South China Sea," TAO: Terrestrial, Atmospheric and Oceanic Sciences, vol. 17, no. 4, p. $815,2006$.

[19] J. Wei, Y. Fang, H. Lu et al., "Distribution and characteristics of natural gas hydrates in the Shenhu Sea Area, South China Sea," Marine and Petroleum Geology, vol. 98, pp. 622-628, 2018.

[20] S. G. Wu, G. X. Zhang, Y. Y. Huang, J. Liang, and H. K. Wong, "Gas hydrate occurrence on the continental slope of the northern South China Sea," Marine and Petroleum Geology, vol. 22, no. 3, pp. 403-412, 2005.

[21] S. X. Yang, H. Q. Zhang, N. Y. Wu et al., "High concentration hydrate in disseminated forms obtained in Shenhu area, north slope of South China Sea," in Proceedings of the 6th International Conference on Gas Hydrate (ICGH2008), Vancouver, British Columbia, Canada, 2008.

[22] J. Ye, J. Wei, J. Liang, J. Lu, H. Lu, and W. Zhang, "Complex gas hydrate system in a gas chimney, South China Sea," Marine and Petroleum Geology, vol. 104, pp. 29-39, 2019.

[23] G. X. Zhang, Y. Y. Huang, Y. H. Zhu, and B. H. Wu, "Prospect of gas hydrate resources in the South China Sea," Marine Geology and Quaternary Geology, vol. 22, no. 1, pp. 75-82, 2002.

[24] G. Zhong, J. Liang, Y. Guo, Z. Kuang, P. Su, and L. Lin, "Integrated core-log facies analysis and depositional model of the gas hydrate- bearing sediments in the northeastern continental slope, South China Sea," Marine and Petroleum Geology, vol. 86, pp. 1159-1172, 2017.

[25] P. Su, J. Liang, J. Peng, W. Zhang, and J. Xu, "Petroleum systems modeling on gas hydrate of the first experimental exploitation region in the Shenhu area, northern South China Sea," Journal of Asian Earth Sciences, vol. 168, pp. 57-76, 2018.

[26] J. Wang, S. Wu, X. Kong, Q. Li, J. Wang, and R. Ding, "Geophysical characterization of a fine-grained gas hydrate reservoir in the Shenhu area, northern South China Sea: integration of seismic data and downhole logs," Marine and Petroleum Geology, vol. 92, pp. 895-903, 2018.

[27] J. Wang, S. Wu, and Y. Yao, "Quantifying gas hydrate from microbial methane in the South China Sea," Journal of Asian Earth Sciences, vol. 168, pp. 48-56, 2018.

[28] X. J. Wang, T. S. Collett, M. W. Lee, S. X. Yang, Y. Q. Guo, and S. G. Wu, "Geological controls on the occurrence of gas hydrate from core, downhole log, and seismic data in the Shenhu area, South China Sea," Marine Geology, vol. 357, pp. 272-292, 2014.

[29] S. X. Yang, M. Zhang, J. Q. Liang et al., "Preliminary results of China's third gas hydrate drilling expedition: a critical step from discovery to development in the South China Sea," Fire Ice, vol. 15, no. 2, pp. 1-5, 2015.

[30] A. V. Milkov, G. R. Dickens, G. E. Claypool et al., "Co-existence of gas hydrate, free gas, and brine within the regional gas hydrate stability zone at Hydrate Ridge (Oregon margin): evidence from prolonged degassing of a pressurized core," Earth and Planetary Science Letters, vol. 222, no. 3-4, pp. 829-843, 2004.

[31] Z. Zhang and D. McConnell, "Seismic modeling analysis and characterization of a gas hydrate and free gas mixed system in Green Canyon, Gulf of Mexico," in Proceedings of the Annual Offshore Technology Conference, vol. 2, pp. 15301541, Houston, Texas, USA, 2010.

[32] G. Guerin, D. Goldberg, and A. Meltser, "Characterization of in situ elastic properties of gas hydrate-bearing sediments on the Blake Ridge," Journal of Geophysical Research: Solid Earth, vol. 104, no. B8, pp. 17781-17795, 1999.

[33] A. Miyakawa, S. Saito, Y. Yamada, H. Tomaru, M. Kinoshita, and T. Tsuji, "Gas hydrate saturation atSiteC0002,IODP Expeditions 314 and 315, in the Kumano Basin, Nankai trough," Island Arc, vol. 23, no. 2, pp. 142-156, 2014.

[34] J. F. Li, J. L. Ye, X. W. Qin et al., "The first offshore natural gas hydrate production test in South China Sea," China Geology, vol. 1, no. 1, pp. 5-16, 2018.

[35] J. Qian, X. J. Wang, T. S. Collett, Y. Q. Guo, D. J. Kang, and J. P. Jin, "Downhole log evidence for the coexistence of structure II gas hydrate and free gas below the bottom simulating reflector in the South China Sea," Marine and Petroleum Geology, vol. 98, pp. 662-674, 2018.

[36] S. Ming, R. Yang, N. Wu et al., "Structural characteristics in the Shenhu area, northern continental slope of South China Sea, and their influence on gas hydrate," Acta Geologica Sinica, vol. 88, no. 3, pp. 318-326, 2014.

[37] Z. Wei, J. Liang, J.'a. Lu et al., “Accumulation features and mechanisms of high saturation natural gas hydrate in Shenhu area, northern South China Sea," Petroleum Exploration and Development, vol. 44, no. 5, pp. 670680, 2017. 
[38] S. Wang, S. Habin, and Y. Wen, "The global and regional estimation of gas resource quantity in gas hydrates," Progress in Geophysics, vol. 20, no. 4, pp. 1145-1154, 2005.

[39] Q. Xuwen, J. Lu, H. Lu et al., "Coexistence of natural gas hydrate, free gas and water in the gas hydrate system in the Shenhu area, South China Sea," China Geology, vol. 3, no. 2, pp. 210-220, 2020. 